\title{
利用噪声层析成像研究华北克拉通中-西部南段及 邻区祁连造山带地壳 $\mathrm{S}$ 波各向异性速度结构
}

\author{
凌媛 1,2 , 陈凌 $1,2,3^{*}$, 危自根 ${ }^{4}$, 姜明明 5 , 王旭 ${ }^{1,2}$ \\ 1. 中国科学院地质与地球物理研究所岩石圈演化国家重点实验室, 北京 100029 ; \\ 2. 中国科学院大学地球科学学院, 北京 100049 ; \\ 3. 中国科学院青藏高原地球科学卓越创新中心, 北京 100101 ; \\ 4. 中国科学院测量与地球物理研究所大地测量与地球动力学国家重点实验室, 武汉 430077; \\ 5. 中国科学院地质与地球物理研究所地球与行星物理重点实验室, 北京 100029 \\ *通讯作者, E-mail: 1chen@mail.iggcas.ac.cn
}

收稿日期: 2017-02-25; 接受日期: 2017-08-04; 网络版发表日期: 2017-09-18

国家自然科学基金项目(批准号: 41225016、91414301、41688103)和中国科学院战略性先导科技专项(B类)项目子课题(编号: XDB03010802) 资助

\begin{abstract}
摘要利用跨越华北克拉通中-西部南段及邻区祁连造山带的宽频带密集流动地震台阵共64个台站约一年的 连续记录, 采用地震背景噪声层析成像方法, 获得了台阵下方5 35s 的Rayleigh面波和 5 30s 的Love 面波相速度分 布, 并进一步反演获得了地壳 $\mathrm{SV} 、 \mathrm{SH}$ 波速度和径向各向异性 $\left(2 \times\left(V_{\mathrm{sh}}-V_{\mathrm{sv}}\right) /\left(V_{\mathrm{sh}}+V_{\mathrm{sv}}\right)\right)$ 结构图像. 我们的研究结果 显示, 研究区地壳速度结构存在明显的区域差异. 克拉通中部南段地壳结构变化复杂, 广泛存在壳内低速体, 可 能是在中-新生代构造和岩浆活动中被改造的反映. 陕西-山西裂陷区及附近区域的下地壳至壳幔边界表现出强 的正径向各向异性特征, 可能与中-新生代地幔基性-超基性铁镁质物质底侵有关. 克拉通西部鄂尔多斯块体地 壳结构相对简单, 与其稳定的克拉通构造属性相吻合. 该地区浅层为东薄西厚的低速且西向单斜结构, 可能与 鄂尔多斯显生宙时期的整体掀斜以及晚白严世以来遭受的强烈差异剥蚀有关; 中-下地壳速度较高, 不存在显著 壳内低速体, 并表现为大尺度的正径向各向异性特征, 可能还保存了鄂尔多斯块体早期形成时的结构特征. 结 合前人对华北克拉通北段的研究结果, 我们发现克拉通中-西部的南、北段地壳结构相似性和差异性并存, 推测 可能与克拉通形成之前和形成之后, 南、北段各自经历不同的构造过程有关. 在克拉通以西的祁连造山带, 中 地壳存在一近水平且自西向东逐渐减弱的低速层, 可能反映该区域受新生代青藏高原东北缘侧向生长的影响, 在强烈的挤压构造背景下地壳内部发生了垂向叠置和强烈的韧性变形，且不支持与青藏高原中下地壳流有关.
\end{abstract}

\section{关键词华北克拉通, 祁连造山带, 噪声成像, 地壳 $\mathrm{S}$ 波速度结构, 径向各向异性}

\footnotetext{
中文引用格式: 凌媛, 陈凌, 危自根, 姜明明, 王旭. 2017. 利用噪声层析成像研究华北克拉通中-西部南段及邻区祁连造山带地壳S波各向异性速度结构. 中 国科学: 地球科学, 47: 1202-1219, doi: 10.1360/N072017-00070

英文引用格式： Ling Y, Chen L, Wei Z G, Jiang M M, Wang X. 2017. Crustal S-velocity structure and radial anisotropy beneath the southern part of central and western North China Craton and the adjacent Qilian Orogenic Belt from ambient noise tomography. Science China Earth Sciences, 60: 1752-1768, doi: $10.1007 / \mathrm{s} 11430-017-9092-8$
} 


\section{1 引言}

华北克拉通是世界上最古老的克拉通之一, 拥有 形成于30多亿年前的古老地壳岩石(Liu等, 1992). 在 约 18.5 亿年前, 克拉通由东、西两个太古宙陆块通过 中部造山带碰撞拼合而成(Zhao等, 2001, 2005). 现今 华北克拉通四周被不同时期形成的造山带所环绕(图 1). 北侧是二叠纪末期华北克拉通与蒙古地块碰撞形 成的中亚造山带(Xiao等, 2003), 南侧和东侧是三叠纪 华北克拉通和扬子板块碰撞形成的秦岭-大别-苏鲁造 山带( Li等, 1993), 西侧是古生代大洋岛弧俯冲增生与 柴达木及阿拉善块体碰撞形成的祁连造山带(许志琴 等, 1994; Xiao等, 2009).

近年来多学科观测表明, 华北克拉通自显生宙以 来经历了强烈的构造活化, 不仅表现在岩石圈厚度的 减薄, 而且克拉通的稳定性质遭到了破坏 (吴福元等, 2008, 2014; 徐义刚等, 2009; 朱日祥等, 2011). 华北克
拉通破坏表现出显著的空间不均匀性. 克拉通东部在 晚中-新生代发生了广泛的伸展构造变形和岩浆活动 (Xu, 2001, 2007; Wu等, 2005; Chen等, 2006, 2008), 古 生代 $>180 \mathrm{~km}$ 厚的岩石圈已减薄至现今的 $60 \sim 100 \mathrm{~km}$, 是 古老克拉通遭受破坏的最典型地区(Carlson等, 2005). 克拉通中-西部主体保持构造稳定, 在克拉通西部稳 定的鄂尔多斯盆地下保留着厚达 $200 \mathrm{~km}$ 的克拉通型岩 石圈, 仅在环鄂尔多斯裂陷带及邻区发生了岩石圈的 减薄和改造(Chen等, 2009, 2014; Zhao等, 2009; 嘉世 旭和张先康, 2005; Bao等, 2013; Dong等, 2014; Wei等, 2015). 因此, 克拉通中-西部现今表现为厚、薄岩石 圈共存的强烈横向不均匀结构特征(朱日祥等, 2011; Chen等, 2008, 2009). 华北克拉通的破坏, 不仅表现在 岩石圈地幔厚度和性质的改变, 还表现在深部与浅部 的响应, 地壳结构的变形和改造. 华北及周边地壳结 构的详细信息能为全面认识华北克拉通中-新生代的 岩石圈构造活化过程及其动力学机制提供重要约束.

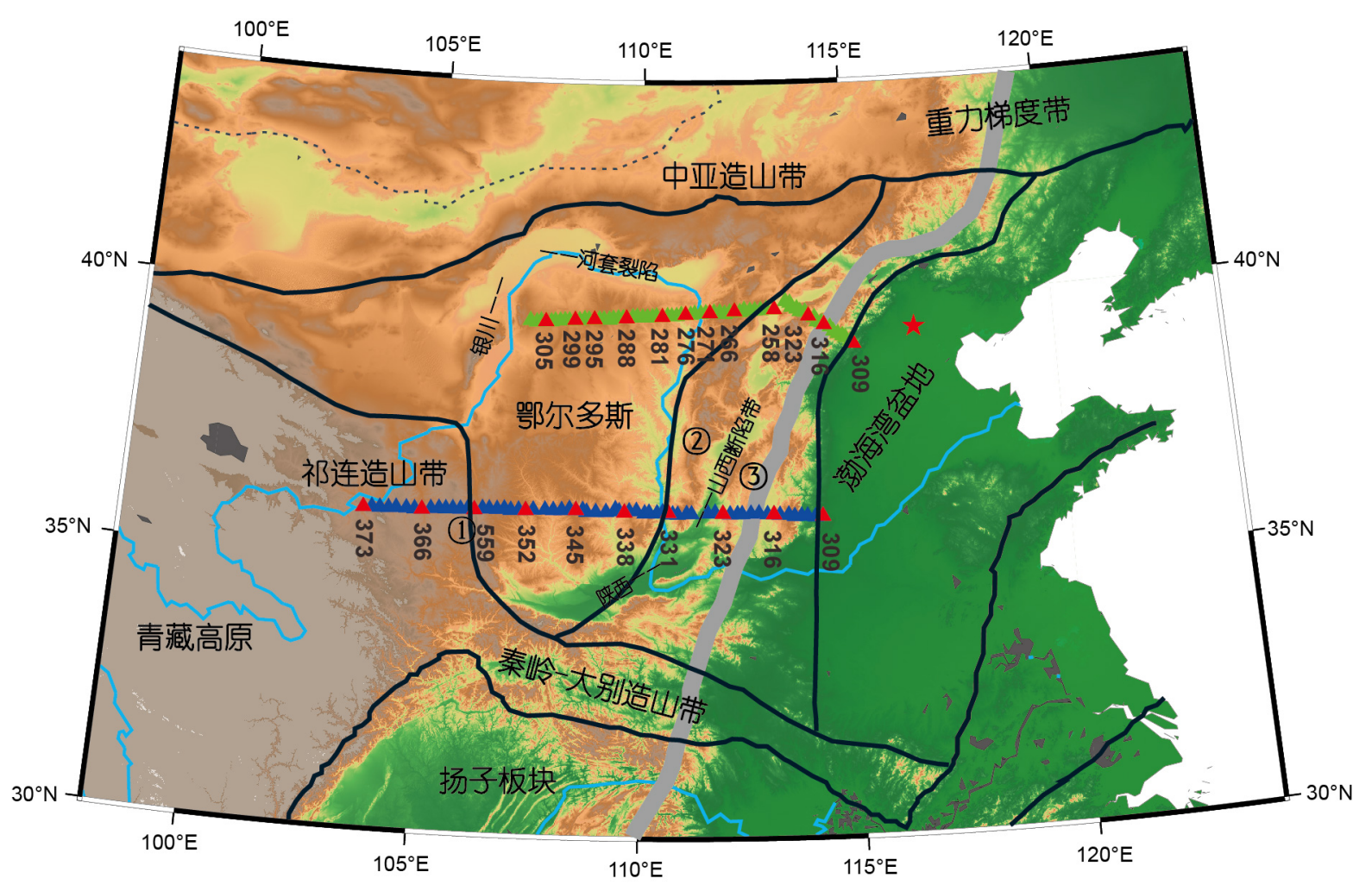

图 1 研究区构造背景和地震台站分布

蓝色三角形代表本研究所用的密集流动地震台阵, 绿色三角形为前人研究华北克拉通北段地壳结构的地震台阵(Cheng等, 2013), 红色三 角形旁边的数字表示其对应的台站号. 黑色实线表示构造边界(Zhao等, 2005), 灰色粗线条表示南北重力梯度带. 标号 (1): 六盘山; (2): 吕梁 山; (3)太行山 
地壳处于地球最外层, 由于压力和温度较低, 能够 很大程度保留地质历史时期构造事件的痕迹, 并叠加 在现今地壳内部演化过程及地球深部动力过程对浅部 结构的影响之中. 华北克拉通地壳大致以南北重力梯 度带为界, 整体呈现出东薄西厚的特征(Wei等, 2016; Chen和Niu, 2016), 并表现出不同岩石学和地球化学 特征(邱瑞照等, 2004). 东部地壳受到明显改造, 西部 鄂尔多斯块体保持着稳定大陆的典型特征. 克拉通 东、中、西三部分地壳结构平均厚度分别为33、37和 $42 \mathrm{~km}$, 平均泊松比分别为 $0.268 、 0.267$ 和 0.264 (危自根 等, 2015). 地壳厚度和泊松比异常主要分布在裂陷区 以及构造边界带处(危自根等, 2015; Wang等, 2014), 与 显生宙复杂的构造演化过程、岩石圈结构改造和破坏 的空间不均匀性相关(Huang等, 2009; Yu等, 2012; Chen 等, 2014). 然而由于克拉通中、西部的结构复杂性以 及观测资料的不足, 现有的研究对该区域的精细地壳 速度结构的认识尚不完善, 比如鄂尔多斯壳内低速体 问题备受关注并存有争议. 接收函数波形反演和噪声 层析成像研究发现, 鄂尔多斯块体地壳内部存在低速 体, 其具体形态和展布范围表现出空间差异性(Zheng 等, 2009; 朱日祥和郑天愉, 2009; Cheng等, 2013); 而接 收函数共转换点叠加成像结果却显示, 鄂尔多斯不存 在壳内低速层, 并认为其北部 (约 $37.5^{\circ} \mathrm{N} \sim 40^{\circ} \mathrm{N}$ )中-下 地壳中普遍观测的负震相与厚沉积层的多次波响应 有关(Wang等, 2014). 对鄂尔多斯壳内低速体存在与 否的争议, 制约了对华北克拉通西部地壳结构和构造 演化的认识.

21 世纪以来, 地震背景噪声干涉成像方法被广泛 应用于地壳-上地幔顶部结构研究. 该方法通过噪声互 相关主要提取地震台站对之间基阶面波的经验格林 函数, 反演地下 $\mathrm{S}$ 波速度结构. 噪声成像方法不同于传 统地震面波方法受天然地震时空分布的限制(Yao等, 2006), 具有可获得丰富的短周期面波信号、且能量 强易于被观测(Shapiro和Campillo, 2004), 并可结合接 收函数等其他方法开展联合反演等优点(Liu等, 2014). 面波群速度常被用来研究大尺度区域结构, 相速度因 其高精度而适于研究区域地壳精细结构(Yao等, 2006, 2008). 此外, 采用噪声成像方法分别反演地壳垂直极 化(SV)和水平极化 $(\mathrm{SH})$ 的 $\mathrm{S}$ 波速度结构, 可进一步获 得地壳径向各向异性结构特征. 这些信息是认识区域 地壳应力分布、岩石组成, 以及可能存在的部分熔融
分布等的重要依据. 对于稳定大陆区域, 地壳各向异 性可能反映了该区域最后一次大规模地质构造活动 的影响; 对于构造活动区域, 地壳各向异性则可能主 要体现了正在进行的构造活动过程(常利军等, 2008). 目前, 基于噪声互相关对地壳-上地幔顶部 $\mathrm{S}$ 波速度和 径向各向异性结构展开了大量的研究, 如Xie等(2013) 在青藏高原东部和扬子克拉通西部、Fu等(2015)在华 北克拉通北部和Bensen等(2009)在美国的研究等. 这 些研究为进一步探讨区域构造演化和变形过程及机 制提供了基础观测约束.

本文利用横跨华北克拉通中-西部南段及其西侧 祁连造山带近东-西向分布的密集流动地震线性台阵 连续记录, 对任意两两台站噪声记录的垂直分量数据 进行互相关和叠加并提取了Rayleigh面波相速度频散 曲线, 对切向分量数据做相应处理提取了Love面波相 速度频散曲线, 进而获得了研究剖面5 35s 的Rayleigh 面波和 5 30s 的Love面波相速度分布. 基于前人利用 接收函数研究约束的地壳厚度和平均 $V_{\mathrm{p}} / V_{\mathrm{s}}$ 波速比先 验信息, 反演获得了地壳SV波和 SH波速度及径向各 向异性结构图像, 进一步探讨克拉通内外地壳结构变 化特征及构造意义. 并结合前人研究, 对华北克拉通 中-西部的南、北段的地壳结构进行了相似性和差异 性对比.

\section{2 噪声资料和分析方法}

本文用于提取面波信息的背景噪声数据, 来源于 中国科学院地质与地球物理研究所布设的一条密集 流动地震台阵的连续记录. 此项目由国家自然科学 基金委员会“华北克拉通破坏”(Destruction of the North China Craton project)重大研究计划支持. 该流动地震 台阵由 64 个宽频带地震台站组成, 命名为309到363(缺 $326)$, 从河南鹤壁到甘肃兰州呈近东西走向 $\left(26^{\circ} \mathrm{N}\right)$ 横 穿华北克拉通中、西部及其紧邻的祁连造山带(图1). 该台阵平均台间距约为 $15 \mathrm{~km}$, 各台站观测周期为从 2006年12月至 2008 年 4 月的10 16个月不等.

本文采用地震背景噪声分析方法提取台站对间的 面波经验格林函数信号. 理论和实际应用都表明, 台站 对之间的经验格林函数(EGF) 可通过对长时间叠加的 噪声互相关函数求导获得, 具体可简单表述为(Sabra 等, 2005; Campillo和Roux, 2014): 


$$
\begin{aligned}
\frac{\mathrm{d} C_{A B}(t)}{\mathrm{d} t}= & -\hat{G}_{A B}(t)+\hat{G}_{B A}(-t) \\
& \approx-G_{A B}(t)+G_{B A}(-t),
\end{aligned}
$$

式中, $C_{A B}(t) 、 \hat{G}_{A B}(t)$ 和 $G_{A B}(t)$ 分别表示 $\mathrm{A} 、 \mathrm{~B}$ 两个台站对 间的背景噪声互相关函数、经验格林函数(EGF)和真 实的格林函数. 我们恢复面波信号的噪声数据处理过 程参照了Bensen等(2007)提出的经典处理流程. 首先 是数据预处理. 将各台站的三分量原始数据切成时间 长度为一天的数据文件, 去除大地震 $(M>6.5)$ 的记录, 进行重采样将采样频率由 $40 \mathrm{~Hz}$ 降到 $10 \mathrm{~Hz}$, 去除仪器响 应、去均值、去倾斜分量, 宽频带滤波到 $0.5 \sim 50 \mathrm{~s}$, 并

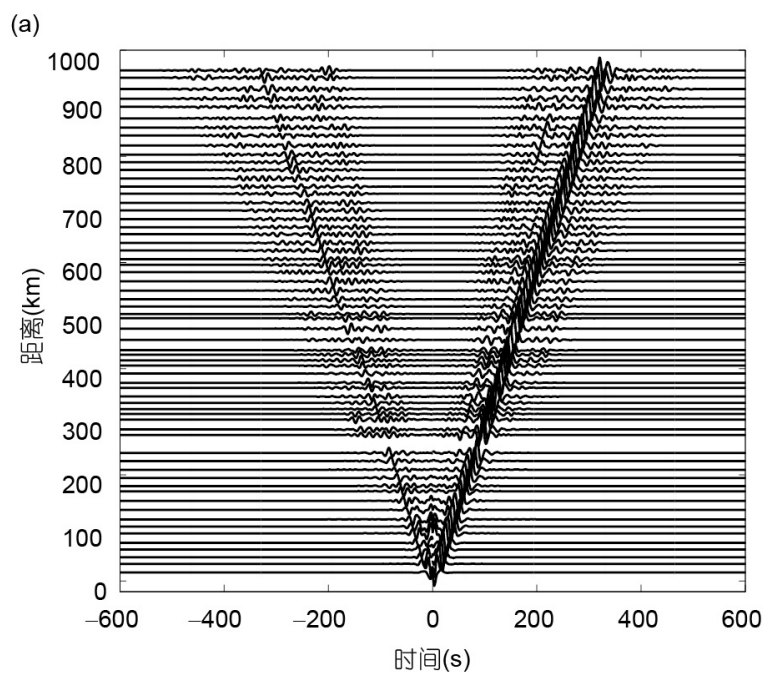

利用滑动绝对平均归一化方法(Running-absolute-mean normalization)对滤波后的数据进行时域规则化和频 谱白噪声化等预处理. 其次是互相关和叠加处理. 对 任意台站对每一天的垂直分量进行互相关, 得到包含 Rayleigh面波信号的互相关函数; 将水平分量旋转至 切向分量并进行互相关, 获得包含Love面波信号的互 相关函数. 将每一台站对观测周期内的所有互相关数 据进行叠加, 以有效减少由于噪声源的季节性分布不 均匀等带来的影响, 提高信噪比. 基于式(1), 从叠加 后的互相关函数分别提取基阶Rayleigh和Love面波的 EGF. 图2a展示了 309台(剖面最东边的台站)与其他所

(b)
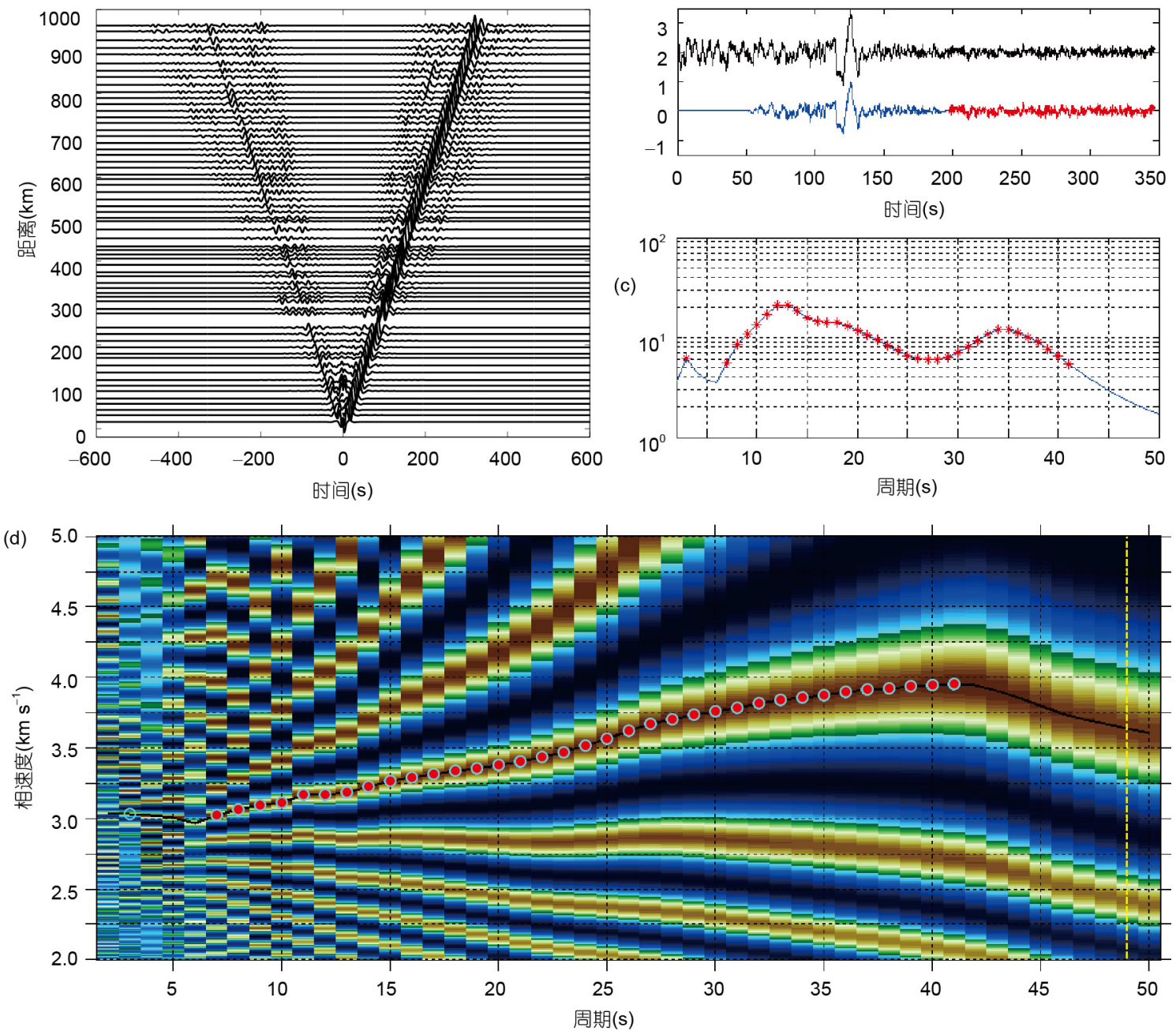

图 2 提取面波频散曲线示例

(a) 309 号台站与其他所有台站之间 10 30s 垂直分量约一年的互相关函数, 考虑群速度窗 2 $5 \mathrm{~km} \mathrm{~s}^{-1}$, 结果按台间距排列; (b) 台站对 345 368 之间Rayleigh面波经验格林函数(黑色), 蓝色波形为信号段, 红色波形为噪声段; (c) 为(b)中相应的信噪比, 红色星号标记信噪比大于 5 的周 期范围; (d) 该台站对间Rayleigh面波相速度频散曲线的提取. 黄色虚线表示台间距是该周期波长的1.5倍, 红色实心圆表示最终选取的相速 度频散曲线 
有台站之间的 $10 \sim 30 \mathrm{~s}$ 垂直分量互相关函数, 可以看到 明显的Rayleigh面波信号.

\section{3 面波相速度频散分析}

\section{1 频散曲线测量}

本文基于基阶面波格林函数的时间域谐波远场 近似, 利用图形转换技术(Yao等, 2006)由 $\mathrm{EGF}$ 提取 Rayleigh和Love面波相速度频散曲线(图2d). 对互相 关函数正支 (因果信号) 和负支(非因果信号)平均后的 对称信号(Yang等, 2007)进行求导得到经验格林函数. 对 $2 \sim 50 \mathrm{~s}$ 每间隔 $1 \mathrm{~s}$ 的周期, 进行带宽为 $0.4 \mathrm{~s}$ 的窄带滤波. 在挑选频散曲线时, 我们综合考虑了远场近似、信噪 比以及频散曲线的连续性. 对一特定频率的挑选标准, 台间距至少超过1.5倍波长, 信噪比大于5(图2c). 此处 信噪比的定义是信号窗内信号包络的最大振幅与信 号窗之后 $150 \mathrm{~s}$ 时间长度范围内噪声(图2b)包络的平均 振幅之比, 信号窗由群速度窗决定, 如 $2 \sim 5 \mathrm{~km} \mathrm{~s}^{-1}$. 此外, 我们还参考了前人在华北克拉通区域的研究结果, 考 虑了不同构造背景下台站对之间面波相速度频散曲 线的特征. 一般而言, 盆地内台站对之间的相速度频 散曲线在短周期时速度值相对较小, 中长周期时速度
值随着周期的增大而快速增大, 整体变化趋势较陡; 山地内台站对间的频散曲线在短周期时速度值相对 较大, 随着周期的增大, 速度值缓慢增大, 变化趋势较 缓; 山地与盆地台站对间的频散曲线的速度值及整体 变化趋势介于上述两种情况之间(Cheng等, 2013).

已有研究表明, 单一持续噪声源可能影响基于噪 声互相关提取的频散曲线的可靠性. 比如, 在日本九 州岛存在一个位置固定、频率范围 $0.07 \sim 0.12 \mathrm{~Hz}$ 、能 量集中在 $10 \mathrm{~s}$ 附近、传播速度约 $2.75 \mathrm{~km} \mathrm{~s}^{-1}$, 且由于火 山震颤引起的单一持续噪声源(Zeng和 Ni, 2010, 2011; 王伟涛等, 2012). 在日本、朝鲜半岛和中国东部与该 噪声源呈特定方位角分布的台站对之间的噪声互相关 函数的因果信号或非因果信号中, 面波信号可能会被 该持续噪声源信号混染, 无法分离, 以致于利用对称信 号提取的相速度和群速度频散曲线在 $10 \mathrm{~s}$ 周期附近都 出现明显的偏差, 尤其是群速度(Zheng等, 2011). 本文 分析了日本持续噪声源对提取频散曲线精度的影响. 图3展示了研究测线东部的台站对311 324间Rayleigh 面波相速度(方框)和群速度(五角星). 基于噪声互相 关函数的负信号、正信号和对称信号所提取的频散 曲线分别用蓝色、黑色和红色表示. 其中, 蓝色频散 曲线不会受日本噪声源信号的影响. 很明显, 三者都

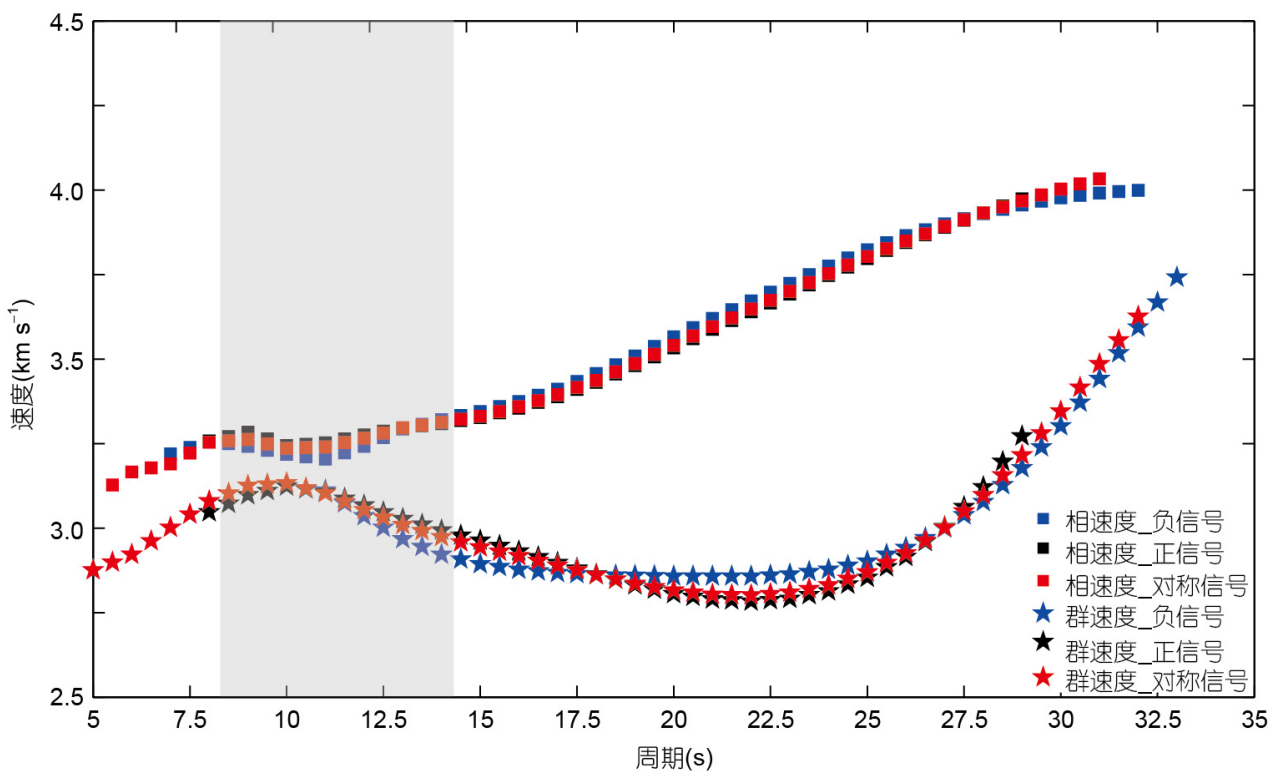

图 3 日本噪声源对频散曲线测量的影响分析

台站对311 324之间的Rayleigh面波频散曲线. 方框表示相速度, 五角星表示群速度, 相对应的蓝色、黑色和红色分别表示基于噪声互相关 函数的负信号、正信号和对称信号所提取的频散曲线. 其中, 蓝色频散曲线不需要考虑日本噪声源信号的影响. 浅灰色区域对应日本噪 声源的频率范围 
表现出很好的一致性, 偏差较小. 在所有频段内, 相对 于红色频散曲线(对称信号), 基于单支信号(蓝色和黑 色曲线)获得的相速度和群速度频散曲线的偏差分别 为 $<40 \mathrm{~m} \mathrm{~s}^{-1}(1.2 \%)$ 和 $<60 \mathrm{~m} \mathrm{~s}^{-1}(2 \%)$. 因此, 我们认为日本 噪声源对本文的数据不存在明显的影响, 可以不予以 特殊处理.

\section{2 相速度结构成像}

台站对之间面波频散反映的是其所经路径介质 的平均速度结构信息. 本文利用阻尼最小二乘方法(杨 文采, 1997)进行一维台阵层析成像反演, 得到研究剖 面下方相速度结构. 在反演之前, 首先将所有频散曲 线按区域分组, 去除明显偏离区域主体特征的异常频 散曲线. 然后将 64 个台站位置投影到 $36^{\circ} \mathrm{N}$, 进行网格 划分, 得到 63 个网格点. 在构建走时慢度方程时, 考虑 了路径偏离直线的效应, 将所有台站对之间的球面距 离投影到 $36^{\circ} \mathrm{N}$ 剖面上. 为了保证结果的可靠性, 在第 一次反演之后, 计算反演过程中所有路径上产生的走 时偏差, 再对数据质量进行控制. 此处的路径走时偏 差表示的是, 在某一周期下, 任意格点间的实际走时 与反演之后的理论走时之间的差. 将 $T \leq 15 \mathrm{~s}$ 时偏差大 于 $3.5 \mathrm{~s} 、 T>15 \mathrm{~s}$ 时偏差大于 $4 \mathrm{~s}$ 的频散曲线, 与其相临近 路径的频散曲线作对比. 如果频散曲线值相近, 并符 合已知的地质结构(如厚的沉积盆地, 短周期面波速度 值较小), 则表示该频散曲线反映的是真实的局部结构 特征, 否则予以舍弃. 最终分别有1641条Rayleigh面波 和1609条Love面波相速度频散曲线被用于相速度结 构反演, 格点下方不同周期的面波相速度频散曲线数 目具体分布情况如图 $4 a$ 和 $b$ 所示. 图 $4 \mathrm{c}$ 和 $d$ 为最终获得 研究剖面5 35s Rayleigh面波和5 30s Love面波相速度 分布图像. 图5 展示了 Rayleigh和Love面波在 $8 、 15$ 和 $25 \mathrm{~s}$ 三个周期的路径走时偏差分布的直方图统计, 其均 方根分别为 $0.78 、 0.76 、 1.41 \mathrm{~s}$ 和 $0.88 、 0.58 、 0.82 \mathrm{~s}$.

结果显示, Rayleigh和Love面波相速度分布总体 表现出相似的特点, 与研究区大尺度地质结构特征相 符合. 面波相速度的敏感深度随着周期的增大而增加. 在华北克拉通西部, Rayleigh和Love面波相速度的短 周期低速异常分布与鄂尔多斯盆地浅层结构均相对 应. $15 \mathrm{~s}$ 周期以上, 相速度主要对 $15 \sim 50 \mathrm{~km}$ 深度结构更 敏感. 华北克拉通中、西部和祁连造山带三大构造带 的相速度从东到西随着周期的增大整体呈减小趋势.
相对较大的相速度则往往由于中、下地壳存在高 $\mathrm{S}$ 波 速度结构体或因地壳较薄所致, 因而研究区的面波相 速度分布还在一定程度上反映了地壳厚度总体呈东 薄西厚的变化特征.

\section{S 波速度结构}

\section{1 反演方法}

对于层状地球模型, Rayleigh面波的相速度与频 率和三组模型参数 $(\mathrm{P}$ 波速度、 $\mathrm{S}$ 波速度和密度) 有关, $\mathrm{P}$ 波速度、 $\mathrm{S}$ 波速度和密度是层厚的函数( Schwab 和 Knopoff, 1972). Love面波相速度则与P波速度无关. S波 速度对频散曲线影响占主导作用. 本文采用Herrmann 和Ammon(2002)发展的迭代阻尼最小二乘反演方法, 基于地震学计算程序(Computer Program in Seismology, CPS; Herrmann, 2013)中面波程序包反演S波速度结构. Rayleigh和Love面波相速度分别单独用于反演 $V_{\mathrm{sv}}$ 和 $V_{\mathrm{sh}}$ 结构.

在设置反演的初始模型时, 将地壳设定为厚度为 $1 \mathrm{~km}$ 的均匀层厚模型, 且 $\mathrm{S}$ 波速度由 $1.8 \sim 3.9 \mathrm{~km} \mathrm{~s}^{-1}$ 均匀 增加; 地幔为一层, 速度是 $4.4 \mathrm{~km} \mathrm{~s}^{-1}$, 反演深度为 $80 \mathrm{~km}$. 我们参考了Wei等(2011)基于接收函数 $H-\kappa$ 叠加方法获 得的地壳厚度和平均 $V_{\mathrm{p}} / V_{\mathrm{s}}$ 波速比信息, 每层的 $\mathrm{P}$ 波速 度为 $\mathrm{S}$ 波速度给定的 $V_{\mathrm{p}} / V_{\mathrm{s}}$ 波速比之积, 密度按经验关 系式 $\rho\left(\mathrm{g} \mathrm{cm}^{-3}\right)=0.77+0.32 V_{\mathrm{p}}\left(\mathrm{km} \mathrm{s}^{-1}\right)$ (Birch, 1961) 进行初 置. 迭代反演次数为 20 次, 前 2 次的阻尼因子为 10 , 以 避免模型的过调节, 后 18 次的阻尼因子设置 0.5 . 在反 演过程中, 设定地壳厚度和 $V_{\mathrm{p}} / V_{\mathrm{s}}$ 固定不变, 密度通过 Nafe-Drake关系式更新. 由于衰减对中高频面波频散 的影响一般很小, 且研究区主体(鄂尔多斯)中高频面 波( $<50 \mathrm{~s}$ ) 表现为低衰减、横向变化小的特征(程先琼 等, 2011), 此处不考虑衰减模型.

\section{2 反演结果及不确定性讨论}

为检验反演结果的稳定性, 我们做了一些测试 (图6). 初始模型在具有不同的近地表初始速度(1.8 和 $2.5 \mathrm{~km} \mathrm{~s}^{-1}$, 图 $6 \mathrm{a}$ 和 $\left.\mathrm{b}\right)$, 以及Moho面深度小幅度变化 $( \pm 3 \mathrm{~km}$; 图 $6 \mathrm{c}$ 和 $d)$ 情况下, 对反演结果的影响都非常小. 通过反演, 我们最终获得了沿研究剖面地壳垂直极化 的 SV波速度 $V_{\mathrm{sv}}$ 结构图像(图7b)和水平极化、且极化 方向与剖面走向垂直的 $\mathrm{SH}$ 波速度 $V_{\text {sh }}$ 结构图像 (图7c). 
(a)

Rayleigh面波相速度频散曲线密度

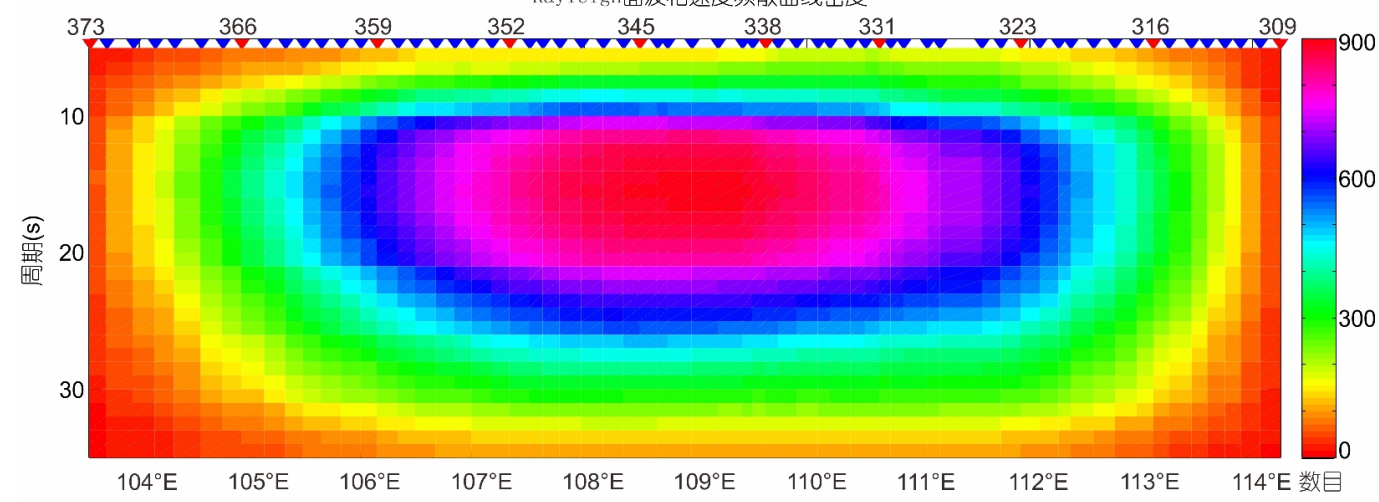

(b)

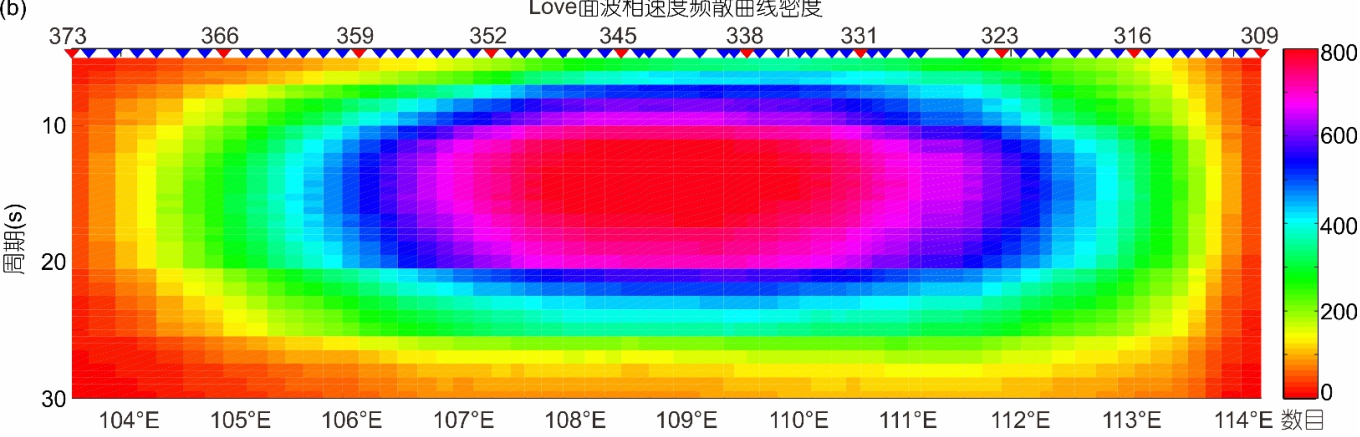

(c)

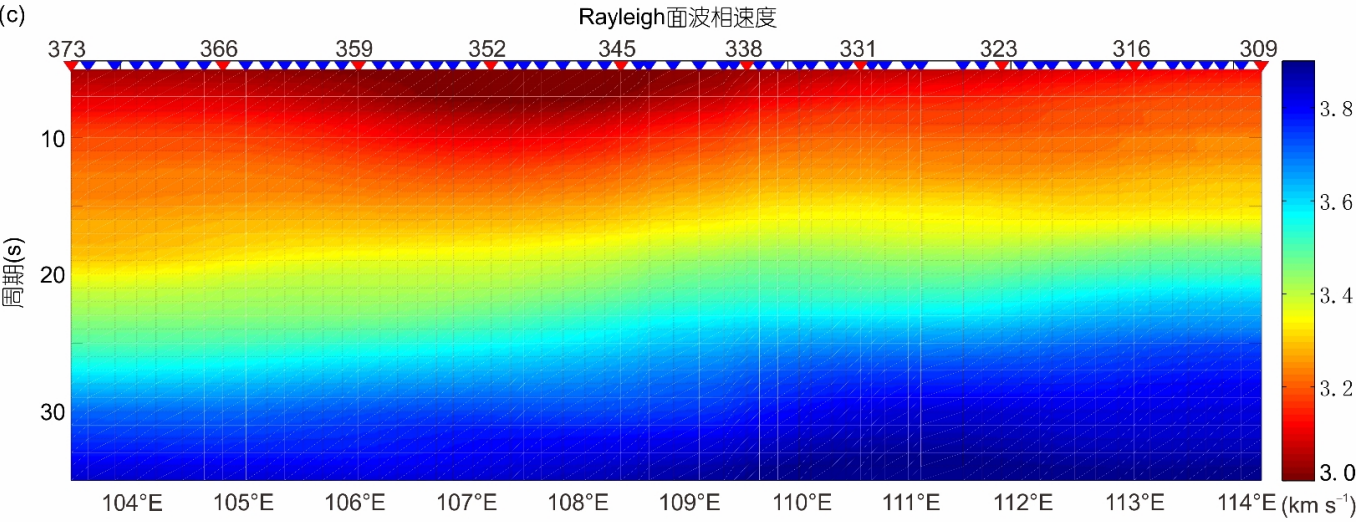

(d)

Love面波相速度

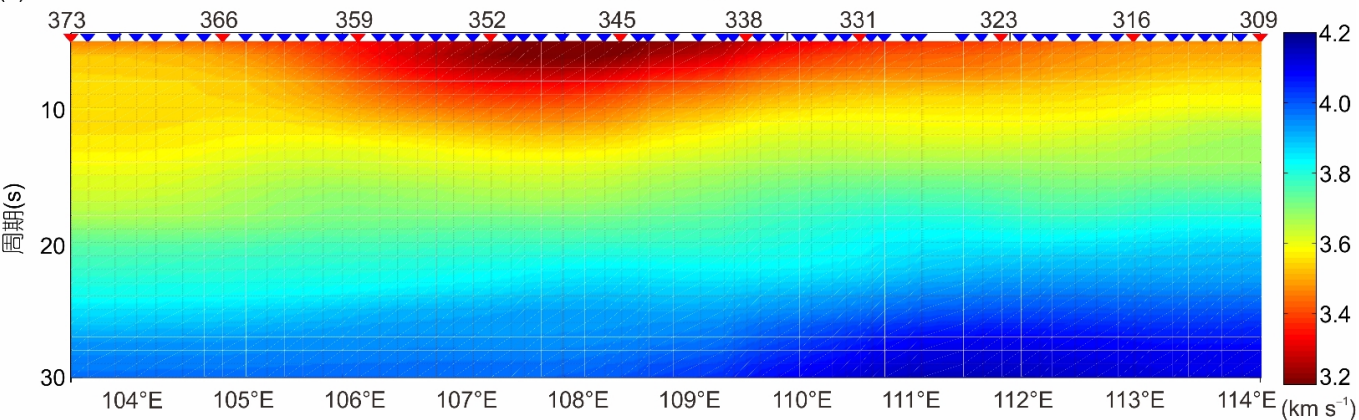

图 4 研究剖面相速度频散曲线密度图和相速度分布图

(a)和(b)分别为研究剖面Rayleigh和Love面波相速度频散曲线密度分布图; (c)和(d)分别为 5 35s Rayleigh面波和5 30s Love面波相速度分布 图像. 剖面最上方的倒三角形为地震台站位置, 其中红色三角形旁边的数字表示其对应的台站号 
(a)

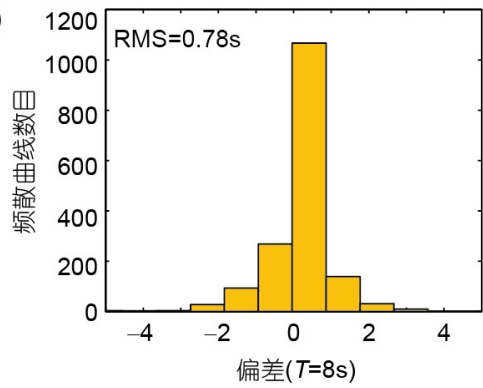

(b)

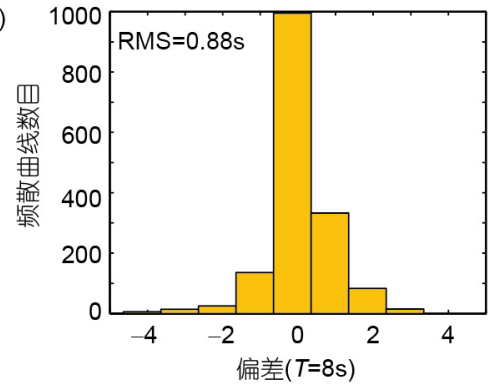

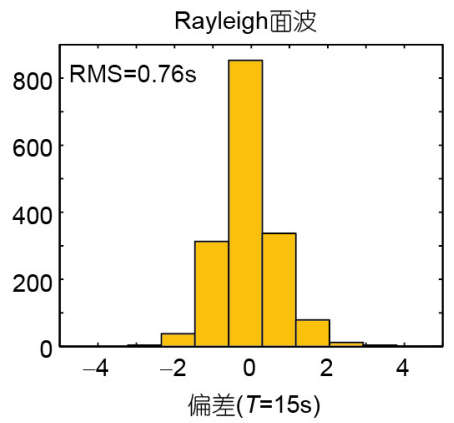

Love面波

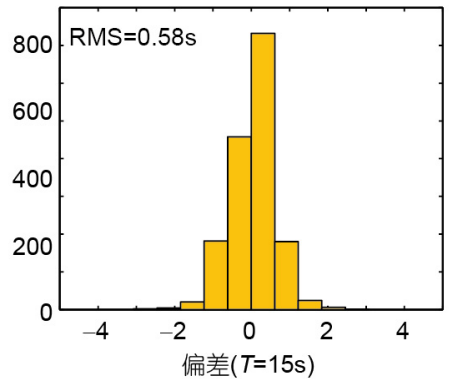

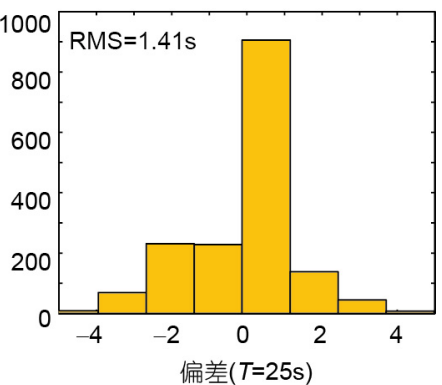

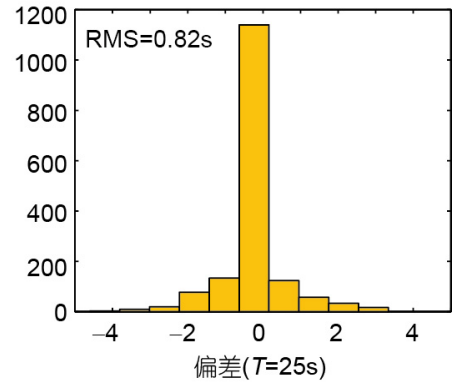

图 5 Rayleigh面波(a)和Love面波(b)8、15和 $25 \mathrm{~s}$ 三个周期的路径走时偏差直方图 RMS为各周期走时偏差的均方根

根据 $V_{\mathrm{sv}}$ 和 $V_{\mathrm{sh}}$ 的相对大小, 由 $2 \times\left(V_{\mathrm{sh}}-V_{\mathrm{sv}}\right) /\left(V_{\mathrm{sh}}+V_{\mathrm{sv}}\right)$ 计算 了径向各向异性(图7d). 本文通过CPS反演时, 假设模 型是各向同性介质。对于横向各向同性介质, Xie等 (2013) 研究发现 $\mathrm{P}$ 波径向各向异性及 $\eta(\mathrm{P}$ 波和 $\mathrm{S}$ 波速度 差异有关的模量)对反演 $\mathrm{S}$ 波径向各向异性的影响是相 互抵消的, 基本在一个标准差不确定范围之内. 并且 Rayleigh面波仅对 $V_{\mathrm{sv}}$ 敏感, 而Love面波主要对 $V_{\mathrm{sh}}$ 敏感, 对 $V_{\mathrm{sv}}$ 表现为弱的敏感度. 因此本文计算径向各向异性 结构的方法是可行的. 另外由于受限于线性台阵, 本 文只能获得与该剖面走向相关的(准)径向各向异性, 即沿研究剖面垂直极化与水平极化(且垂直于剖面方 向)的 $\mathrm{S}$ 波速度差异.

我们的结果显示, 从东到西, 华北克拉通南段中、 西部, 和祁连造山带 $\mathrm{S}$ 波速度结构差异明显. 克拉通中 部南段的地壳速度结构具有强烈的横向和垂向不均 匀性. $V_{\mathrm{sv}}$ 剖面显示(图7b), 最东端的太行山与渤海湾 盆地间的盆山过渡带(309 313台站)下地壳存在厚度 $\sim 12 \mathrm{~km}$ 、平均速度为 $\sim 3.45 \mathrm{~km} \mathrm{~s}^{-1}$ 的显著低速体. 太行 山主体(314 322台站)中地壳存在厚度约 $10 \mathrm{~km}$ 、平均 速度为 $3.52 \mathrm{~km} \mathrm{~s}^{-1}$ 的近水平低速层, 且该低速层向西 倾斜延展到陕西-山西裂陷区的下地壳中, 再往西至吕 梁山该低速异常迅速减弱, 到克拉通中、西块体边界
处时消失. $V_{\mathrm{sh}}$ 剖面(图7c)也观测到了壳内低速体结构. 克拉通中部的径向各向异性结构以陕西-山西裂陷区 及附近区域下地壳至壳幔边界的显著正径向各向异 性为突出特征 $\left(V_{\mathrm{sh}}>V_{\mathrm{sv}}\right.$, 图7d $)$.

在克拉通西部南段, 地壳结构相对简单、均一. $V_{\mathrm{sv}}$ 剖面(图7b)显示, 整个鄂尔多斯浅部为反映盆地沉 积盖层影响的低速层. 该低速层自东向西变厚, 其底 部以约 $1^{\circ} \sim 2^{\circ}$ 的角度向西倾斜. 克拉通西部中-下地壳 速度主要在约3.5 4.0 $\mathrm{km} \mathrm{s}^{-1}$ 范围变化, 明显高于克拉 通中部和祁连造山带的中-下地壳速度. $V_{\mathrm{sh}}($ 图7c)结构 具有与 $V_{\mathrm{sv}}$ 类似的空间变化特征, 中-下地壳 $V_{\mathrm{sh}}>V_{\mathrm{sv}}$, 表 现出较强的正径向各向异性特征. 在鄂尔多斯北段, Cheng等(2013)的噪声层析成像结果显示中-下地壳存 在大尺度低速层, 但我们在南段的结果并没有观测到 地壳内存在明显低速层. 为此我们做了壳内低速层 测试. 如图6e, 在格点338 339的最终S波反演模型(蓝 色)20 30km深度范围内人为地加入低速层(绿色), 绿 色模型相对于蓝色模型的最大偏差不大于 $4 \%$, 相应的 频散曲线见图6f. 在10 30s频段内, 低速层模型的频散 曲线(绿色)相对于频散观测值(红色星形)的偏差主要 在0.6 1\%, 而蓝色频散曲线与观测值间的偏差大部分 $<0.1 \%$. 这表明在该区域并不需要引入壳内低速层来 

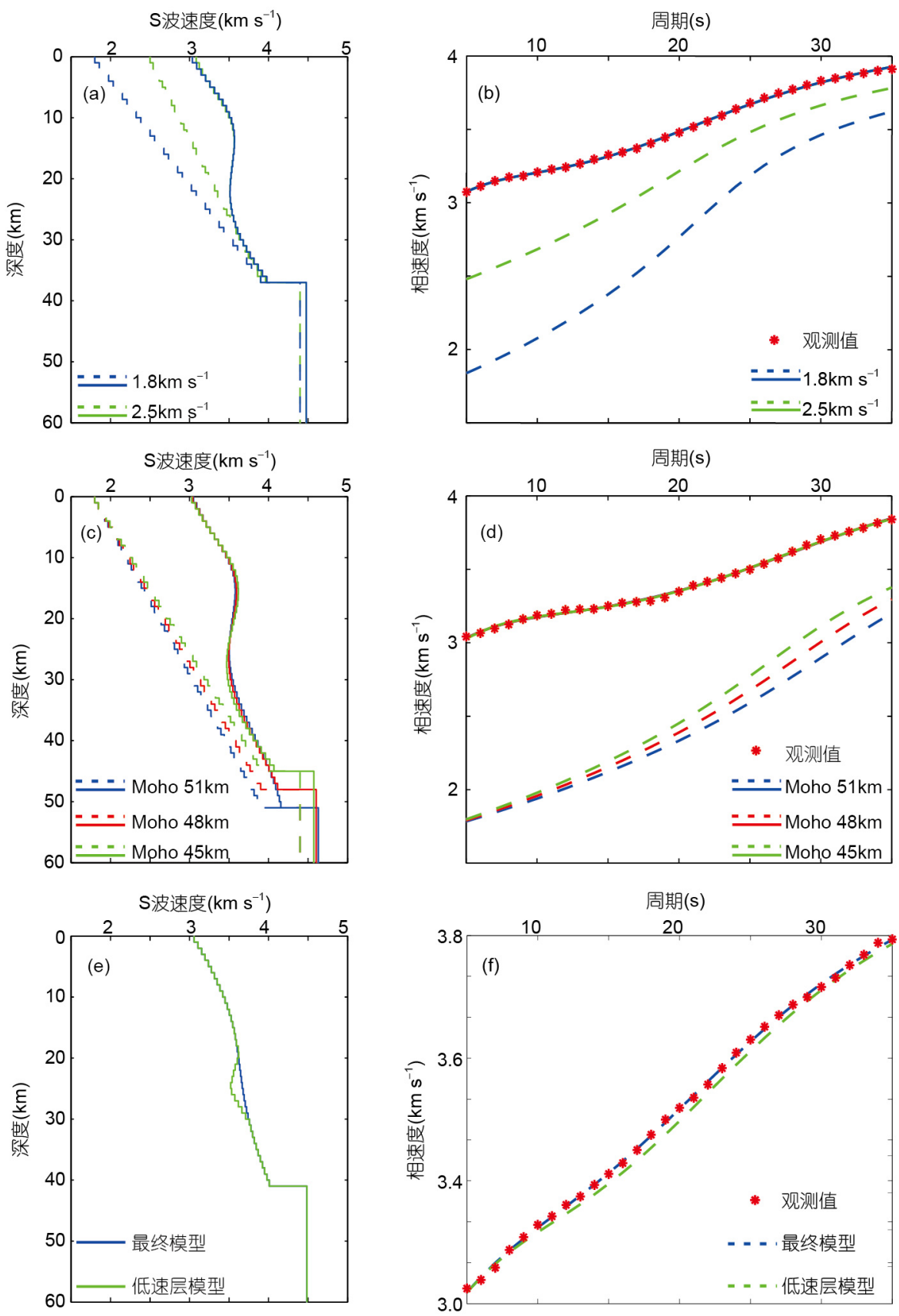

图 6 反演获得的 $S$ 波速度模型((a)、(c)和(e))及相对应的频散曲线((b)、(d) 和 (f))

(a)和(b)中蓝色和绿色线条为格点324 325的近地表初始速度分别是 1.8 和 $2.5 \mathrm{~km} \mathrm{~s}^{-1}$ 的结果; (c) 和(d)中红色、蓝色和绿色线条为格点 371 372 在正常地壳厚度(48土3)km情况下的模型反演结果; (e)和(f)中格点338 339的最终反演结果(蓝色)与具有低速层的模型(绿色)对比. (a) (d)中 虚线和实线分别表示初始模型和反演结果. (b)、(d)和(f)中红色星号表示观测的相速度频散值

解释观测数据.

与克拉通西部相毗邻的祁连造山带, 分布有水平 延展的壳内低速层. $V_{\mathrm{sv}}$ 剖面(图7b)显示, 在该区域中地 壳约20 30km深度处发育一约 $10 \mathrm{~km}$ 厚的低速层, 向东
延展至祁连造山带与克拉通边界区域(365台站附近) 并呈减弱趋势. $V_{\mathrm{sh}}$ 剖面(图7c)也显示约12 22km深度 处有一低速层. 与克拉通中部倾斜的低速体不同的是, 在 $V_{\mathrm{sv}}$ 和 $V_{\mathrm{sh}}$ 剖面中, 祁连造山带的壳内低速层均为水平 

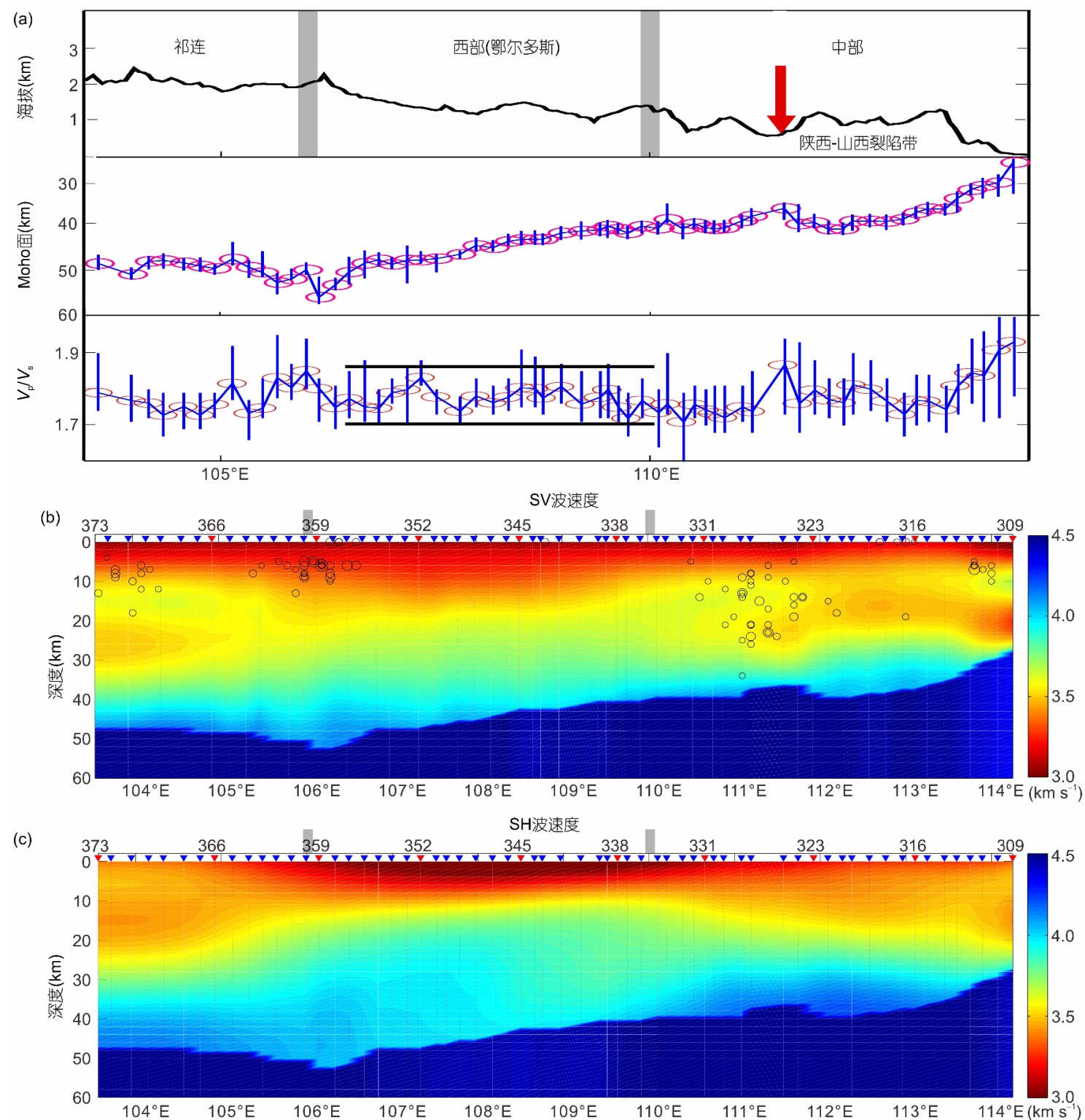

(d)

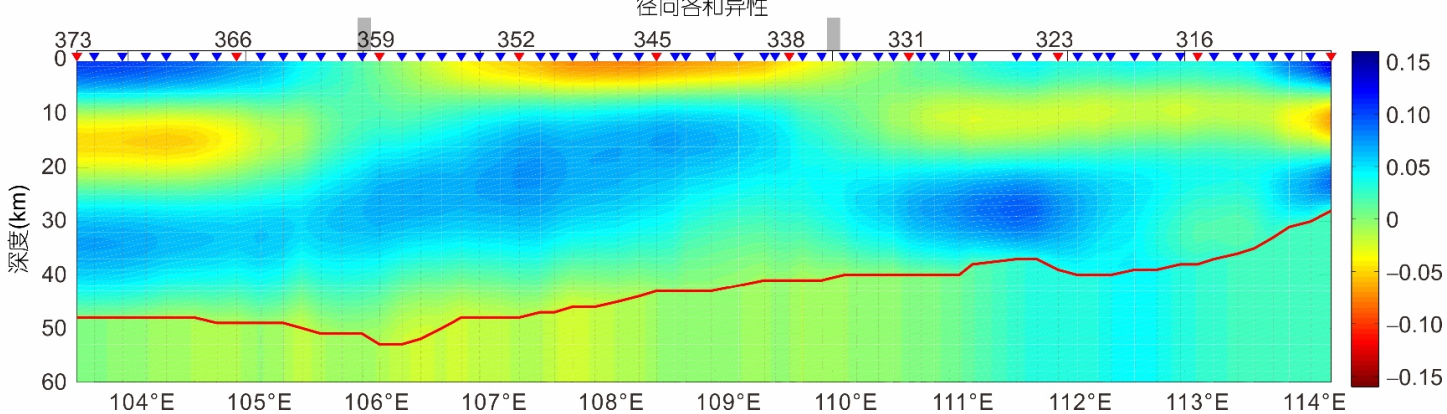

图 7 研究区地壳结构

(a)研究剖面地形、地壳厚度和平均“ $V_{\mathrm{p}} / V_{\mathrm{s}}$ ”波速比(Wei等, 2011); (b)和(c)分别为垂直极化 SV 波和水平极化(垂直于研究剖面方向)SH波 速度结构剖面 $\left(V_{\mathrm{sv}}\right.$ 和 $\left.V_{\mathrm{sh}}\right) . V_{\mathrm{sv}}$ 中黑色空心圆圈为剖面 $\left(36^{\circ} \mathrm{N}\right)$ 南北 $0.3^{\circ}$ 区域内 2000 年以来的 2 级以上地震投影, 数据来源于中国地震信息网 (http://www.csi.ac.cn/publish/main/index.html); (d)径向各向异性结构. 正值表示 $V_{\mathrm{sh}}>V_{\mathrm{sv}}$, 负值表示 $V_{\mathrm{sv}}>V_{\mathrm{sh}}$. 红色实线为(a)中平滑后的地壳厚度 
延展. 另外, 祁连造山带和鄂尔多斯块体具有明显不 同的地壳结构特征, 边界带六盘山断裂带附近区域速 度结构横向变化大, 20km深度以上的速度偏低, 伴随 着较强烈的地震活动性(图7b), 并对应于地壳的显著 增厚和平均泊松比增高(图7a; Wei等, 2011).

为探讨研究区复杂速度结构及强的径向各向异 性结构的可靠性, 并考虑到基于噪声互相关获得的相
速度频散曲线误差一般在 $1 \%$ 左右(Yao和van der Hilst, 2009; Yao等, 2009; Harmon等, 2010; Luo等, 2015), 我 们测试了相速度频散曲线扰动对反演结果的影响. 我 们选取格点324 325, 将其Rayleigh和Love面波相速度 频散曲线(图8a, 红色星号)各自加 $1 \%$ 高斯白噪声 200 次 (图8a, 绿色虚线和蓝色实线), 并分别反演获得相应的 $V_{\mathrm{sv}}\left(\right.$ 图 $8 \mathrm{~b}$, 绿色实线)和 $V_{\mathrm{sh}}($ 图 $8 \mathrm{c}$, 绿色实线)及其平均结
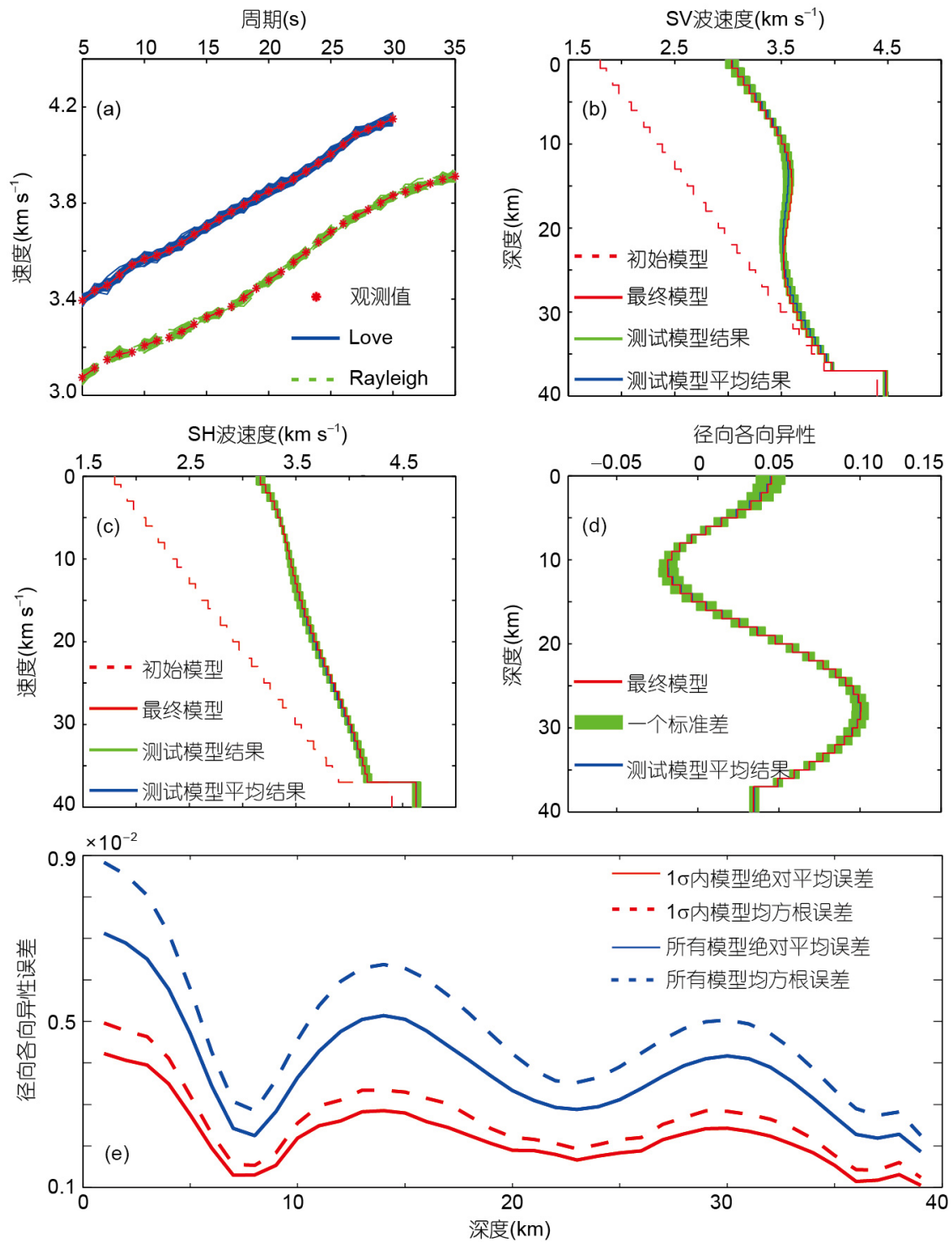

图 8 相速度频散曲线扰动对反演结果影响测试

(a) 324 325格点的Rayleigh和Love面波相速度频散曲线. 绿色实线和绿色虚线分别表示加 $1 \%$ 高斯白噪声的Rayleigh和Love面波相速度频散 曲线, 红色星号为观测值. (b)和(c)分别基于Rayleigh和Love面波反演获得的 $V_{\mathrm{sv}}$ 和 $V_{\mathrm{sh}}$ 结构. 其中红色虚线为初始 $\mathrm{S}$ 波反演模型, 绿色和蓝色实线 分别为 200 次测试的反演结果及其平均值. (d) 径向各向异性结构. 蓝色实线和水平的短绿棒分别表示 200 次测试相应的的径向各向异性的平

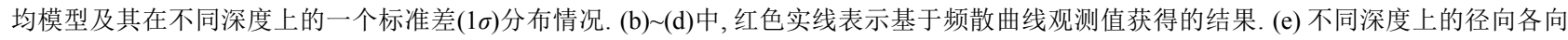
异性误差分布情况. 蓝色和红色曲线分别代表 200 次测试的所有模型和 $1 \sigma$ 内模型的误差结果, 虚线表示均方根误差, 实线表示绝对平均误差 
果(蓝色实线). 通过与直接基于实际观测的频散曲线 (图 8a, 红色星号)的反演结果 (图 $8 \mathrm{~b}$ 和 $\mathrm{c}$, 红色实线)对 比, 可以看到, Rayleigh和Love面波频散曲线扰动测试 的反演结果稳定, 反映的该格点速度结构特征具有一 致性. 图 $8 \mathrm{~d}$ 展示了基于这 200 次测试得到的径向各向 异性结构在不同深度上的平均结果(蓝色实线)及一个 标准差 $(1 \sigma$, 绿色区间)分布情况. 图 $8 \mathrm{~b}$ 和 $\mathrm{c}$ 中, 蓝色实线 都与红色实线非常相近, 图 $8 \mathrm{~d}$ 中两者几乎重合. 图 $8 \mathrm{e}$ 为所有测试模型(蓝色)及 $1 \sigma$ 内模型(红色)相对于最终 模型的径向各向异性绝对平均误差(实线)和均方根误 差(虚线)分布情况. 结果表明, 相速度频散曲线存在 $1 \%$ 的误差可能造成绝对径向各向异性结果 $\pm 1 \%$ 以内 的不确定性. 这对本文关注的中部裂陷区和鄂尔多斯 之下超过 5\%的强径向各向异性特征的判断(分别见下 文5.1和5.2)影响不大.

\section{5 讨论}

本文获得的 $\mathrm{S}$ 波速度结构揭示了华北克拉通中西部南段及祁连造山带的地壳结构特征及其差异性. 总体而言, 华北克拉通中部和祁连造山带的壳内结构 复杂, 都存在显著的壳内低速体, 但两者表现出不同 的结构特征和形态, 可能反映了各自不同的地壳性质 和构造演化过程. 克拉通西部的鄂尔多斯块体地壳结 构相对简单, 未观测到明显的壳内低速体, 与古老克 拉通稳定的构造属性一致.

\section{1 华北克拉通中部南段地壳结构}

华北克拉通中部带作为连接克拉通东、西两部分 的过渡区, 地壳厚度从东边界处 $30 \mathrm{~km}$ 向西快速增厚 到 40km, 结构变化复杂(Wei等, 2011; Wang等, 2014; Bao等, 2013), 是研究和探讨华北克拉通改造和破坏的 重要区域.

本文研究结果显示, 克拉通中部南段陕西-山西 裂陷区及附近区域的下地壳至壳幔边界具有正常的 $V_{\mathrm{sv}}\left(\right.$ 图7b)和偏高的 $V_{\mathrm{sh}}$ (图7c)速度结构, 表现出强的正 径向各向异性特征(图7d). 该裂陷区域由于其自身结 构性质而成为构造薄弱带, 被认为可能发生了深部热 物质上涌、下地壳铁镁质物质增加或壳内存在局部 熔融(Wei等, 2013; Wang等, 2014). 已有研究表明, 该 区域附近地表热流较高(Hu等, 2000), 地壳较薄, 泊松
比较高(危自根等, 2015; Wang 等, 2014), 上地幔S波速 度较低(Jiang等, 2013), 其顶部具有明显的Pn波低速异 常(李志伟等, 2011). 综合本文成像结果和前人观测, 我们推测, 在中-新生代构造和岩浆作用下, 上地幔基 性-超基性物质可能已经上涌至陕西-山西裂陷区的 壳幔边界, 伴随着地壳伸展减薄, 在裂陷区及邻近区 域下地壳底部附近堆积和扩展. 裂陷区附近下地壳 至壳幔边界的强的正径向各向异常可能是由于这些 侵入的富橄榄石地幔各向异性物质的变形引起, 表明 克拉通中部带地壳可能已局部被活化和改造. Guo和 Chen(2016)基于面波和接收函数得到的南北向线性剖 面 $\left(\sim 111^{\circ} \mathrm{E}\right)$ 观测结果认为, 在该区域附近可能存在晚 中生代以来由于地幔铁镁质物质多次底侵形成的壳 幔过渡层, 支持我们的推测.

本文结果还显示, 中部带南段地壳速度结构横向 差异明显, 并广泛分布壳内低速体. 在研究剖面最东 端的太行山与渤海湾盆地间的盆山过渡区域, 中-下 地壳存在较强的低速异常体, 并具有着高泊松比异常 (图7a; Wei等, 2011), 可能与该区域早白严纪岩浆活动 (朱日祥等, 2015)和新生代鹤壁玄武岩分布(Zheng等, 2001)有关. 太行山至陕西-山西裂陷区域观测到较为 连续的中地壳低速层, 可能也与克拉通中部中-新生代 构造活化和岩浆活动(Griffin等, 1998)有关.

\section{2 华北克拉通西部南段地壳结构}

相对于克拉通中部, 西部鄂尔多斯表现为大尺度 的地壳结构特征, 横向变化相对平缓, 而且地壳相对 较厚(主体约40 50km, 图7a, Wei等, 2011), 可能与该区 域长期保持构造稳定有关.

我们观测到克拉通西部地壳的两个主要速度结构 特征. 其一是鄂尔多斯地壳浅部整体表现为厚的低速 单斜结构. 该低速层以 $1^{\circ} \sim 2^{\circ}$ 的小角度向西倾斜, 与自 东向西逐渐加深的Moho面形态有一定的近似性. 这可 能与显生宙时期鄂尔多斯基底带动整个盖层发生整 体掀斜相对应(邓军等, 2005), 以及与自晚白严世以来 鄂尔多斯地块东隆西降、遭受强烈的差异剥蚀改造 有关(刘池洋等, 2006). 鄂尔多斯地壳的另一个主要结 构特征是中-下地壳结构相对简单, 速度较高, 连续性 好, 不存在小尺度的结构不均匀性, 并表现出较强的正 径向各向异性(图 7b d). 鄂尔多斯南段地壳随着地形 的增加而逐渐变厚, 具有相对稳定的泊松比(图7a; Wei 
等, 2011), 地表热流值较低、少地震和岩浆活动(Zhai 和Liu, 2003), 岩石圈厚且高速、岩石圈地幔具有典型 克拉通的结构特征(Chen等, 2014; Jiang等, 2013; Bao 等, 2013; Zhao等, 2009). 我们认为研究剖面鄂尔多斯 地区仍然保持着稳定克拉通的属性, 其地壳结构可能 反映了克拉通早期形成时的结构特征, 显生宙以来还 未被明显改造或者只经历了弱变形.

\section{3 华北克拉通中-西部的南、北段地壳结构对比}

我们的观测结果表明,在华北克拉通南段, 研究区 中部造山带地壳可能受到了局部改造, 西部鄂尔多斯 块体整体保持了稳定的克拉通结构特征和构造属性. Cheng等(2013)同样采用噪声成像方法获得了华北克 拉通北段密集流动台阵(位置见图1)下方的S波速度和 径向各向异性结构图像, 为本文分析对比克拉通中-西 部的南北地壳结构的特征异同提供了信息(图9b d).

克拉通中-西部南、北段的地壳结构特征既存在 相似性又存在差异性(图7和9). 在克拉通中部, 南、北 段均经历了显生宙构造伸展和幔源岩浆底侵作用, 地 壳遭受了明显的改造, 具有较为复杂的速度结构. 南 段以中地壳连续低速层和陕西-山西裂陷区下地壳强 的正径向各向异性为主要特征. 北段的突出特点则是 局部的厚壳幔过渡带(Zheng等, 2008)和径向各向异性 的显著垂向变化(Cheng等, 2013). 西部鄂尔多斯南、 北段总体都具有大尺度、成层性较好、相对简单的 地壳结构, 可能是其古老、稳定地壳特征的体现. 其 浅部都存在较厚的 $1^{\circ} \sim 2^{\circ}$ 西向单斜低速结构, 可能与鄂 尔多斯沉积盆地在显生宙时期整体掀斜的构造过程 相对应. 鄂尔多斯盆地北段地壳底部存在正径向各向 异性局部异常(Cheng等, 2013), 并伴随着 $V_{\mathrm{p}} / V_{\mathrm{s}}$ 波速比 的局部增高、地壳相应增厚等特点(Wei等, 2011), 表 明该区域可能发生了下地壳的局部改造. 鄂尔多斯南 段地壳 $\mathrm{S}$ 波速度结构与径向各向异性具有良好的连续 性, Moho面与地形呈镜像变化, $V_{\mathrm{p}} / V_{\mathrm{s}}$ 波速比横向变化 较小(Wei等, 2011). 此外, 南段不存在明显的壳内低速 层, 与北段明显不同. 显著的壳内低速层并不贯穿整 个鄂尔多斯.

华北克拉通中-西部地壳结构的南北差异特征, 可能反映了该区域形成初期就具有的结构差异, 以及 显生宙以来多期构造事件对南北地壳结构的差异影 响. 19.5 亿年前阴山-鄂尔多斯块体碰撞拼合(Zhao
等, 2005; 李三忠等, 2016)、古生代末古亚洲洋的闭合 引起华北克拉通与蒙古地块碰撞拼合(Xiao等, 2003; Davis等, 2001)等构造事件可能主要影响克拉通北段 的地壳结构; 而三叠纪扬子板块向华北克拉通俯冲碰 撞则使克拉通南缘和东南缘受到较大程度的改造(如 朱日祥等, 2012及其中的文献), 可能已经影响到了我 们在克拉通中部南段的研究区域. 另外, 新生代时期 鄂尔多斯块体的逆时针旋转 (Zhang 等, 1998; 范俊喜 等, 2003), 也可能对中部带裂陷系南、北段的发育产 生差异影响. 然而要全面认识克拉通中-西部地壳结 构的南北差异性及其反映的构造演化特征, 还需要进 一步深入研究. 比如壳内低速层的具体形态和分布范 围及其成因, 需要开展高精度的三维速度结构成像.

\section{4 祁连造山带}

祁连造山带是青藏高原东北缘的主体和前缘部 分, 在印度-欧亚板块持续碰撞影响下, 地表变形强烈, 壳幔结构复杂(张培震等, 2004; 赵国泽等, 2010; 李松 林等, 2002; Li等, 2011; Jiang等, 2014). 鉴于其特殊的 地理位置和复杂结构特征, 祁连造山带成为研究青藏 高原侧向生长和扩展及其与周边块体相互作用的重 要场所. 祁连造山带东南部具有厚的地壳( $50 \mathrm{~km}$, 图 7a, Wei等, 2011) 以及与鄂尔多斯显著不同的地壳S波 速度结构. 该区域最显著的特征是中地壳存在 $10 \mathrm{~km}$ 厚的呈水平延展、且自西向东逐渐减弱的低速层(图 7b), 并表现为低阻的电性结构 (汤吉等, 2005; 赵国泽 等, 2010). 人工源地震测深(李松林等, 2002)、接收函 数(陈九辉等, 2005)等研究在该区域附近也观测到了 壳内低速层.

祁连造山带东南部壳内低速层的形成机制是认识 青藏高原东北缘扩展动力学过程的重要约束. 前人面 波层析成像研究在祁连造山带西北部也发现了壳内低 速体, 并认为是由于印度板块向欧亚大陆俯冲碰撞的 远程效应导致的壳内部分熔融, 代表了高原内部低速 层形成的早期阶段(Jiang等, 2014; Bao等, 2013; Li 等, 2014). 祁连造山带东南部发育着近水平的中地壳低 速层, 且不存在明显的高热流值 $(\mathrm{Hu}$ 等, 2000)和高泊松 比 $(<0.28$, Wei等, 2011)特征. 这表明, 该区域的壳内低 速层可能并不是由于地壳熔融引起, 青藏高原中下地 壳的东北向流动可能尚未影响到此. 赵国泽等(2010) 通过大地电磁的研究发现, 该区域地壳内的低阻异常 

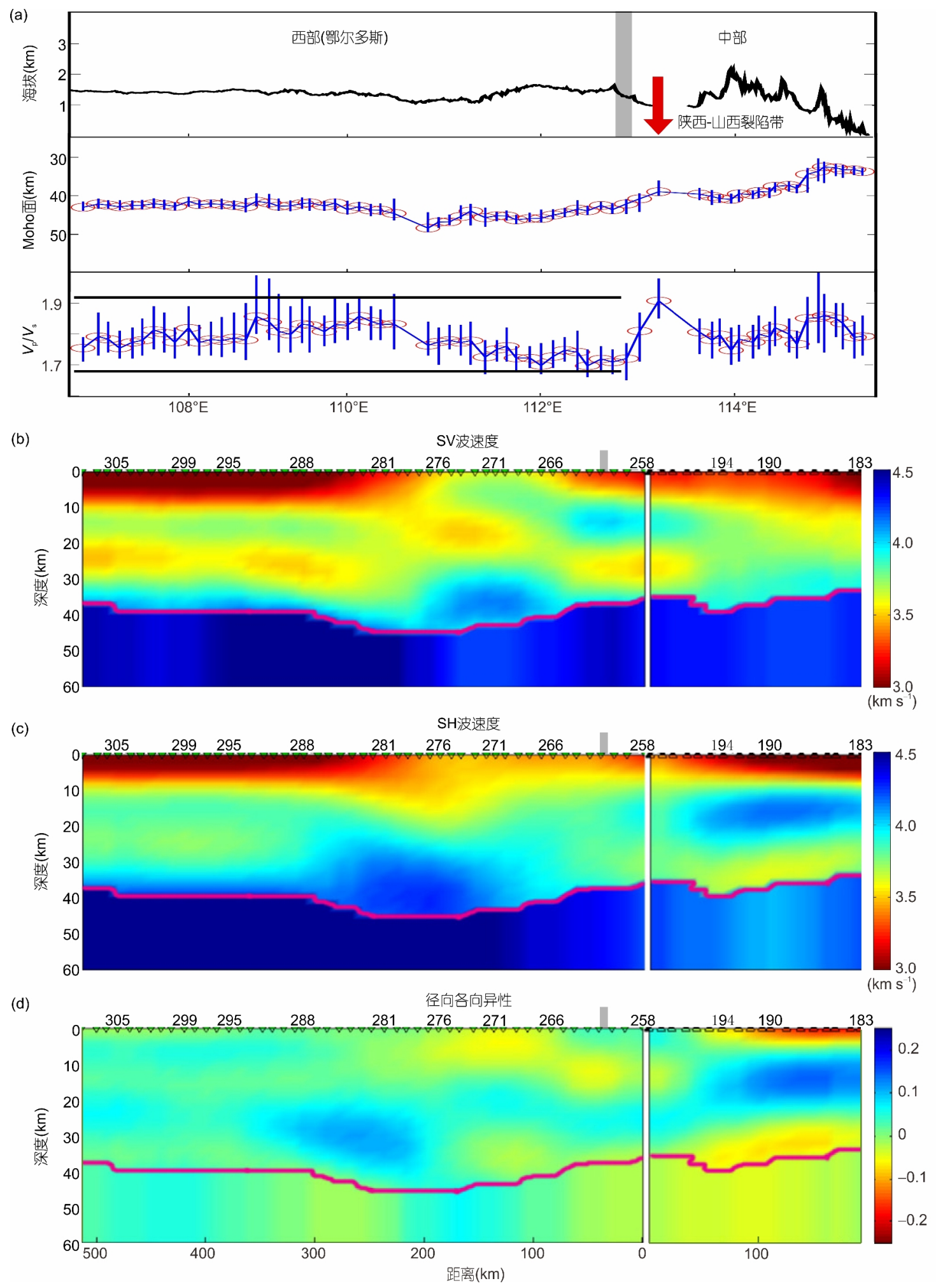

图 9 华北克拉通中-西部北段地壳结构

台阵位置见图1中绿色三角形. (a) 剖面地形、地壳厚度和平均 $V_{\mathrm{p}} / V_{\mathrm{s}}$ 波速比(Wei等, 2011); (b) 和(c) 垂直极化SV波和水平极化(垂直于剖面方 向)SH波速度结构剖面 $\left(V_{\mathrm{sv}}\right.$ 和 $\left.V_{\mathrm{sh}}\right)$; (e) 径向各向异性结构. (b) (d) 修改自 Cheng等(2013) 
可能是由于一个规模较大的壳内滑脱带或剪切带造 成的. 深地震反射研究认为, 青藏高原东北缘可能通 过一系列近水平的壳内拆离断层来调节地壳缩短变 形(高锐等, 2011; Guo等, 2016). 祁连造山带东南部具 有较强的地震活动性(图7b), 近水平的中地壳低速层 自西向东呈减弱趋势, 止于祁连造山带与鄂尔多斯块 体边界带附近. 另外, 在该边界处的六盘山断裂带区 域, 20km深度以上的地壳速度较低、地震活动强烈, 地壳平均 $V_{\mathrm{p}} / V_{\mathrm{s}}$ 波速比起伏变化, Moho面明显下凹、地 壳局部加厚(图7; Wei等, 2011; Wang等, 2014). 综合以 上结果我们推测, 可能主要受印度板块俯冲碰撞影响, 青藏高原的东北向生长受到了坚硬的鄂尔多斯块体 的阻挡. 其东北缘前端在强烈的挤压构造背景下, 中 上地壳叠置增厚, 发生剪切韧性形变, 导致中地壳产 生近水平并且自西向东变弱的低速层结构.

\section{6 结论}

本文利用长度近 $1000 \mathrm{~km}$ 的密集宽频带流动地震 台阵所记录的背景噪声数据, 通过噪声层析成像获得 了华北克拉通中-西部南段及其邻区祁连造山带二维 $\left(36^{\circ} \mathrm{N}\right)$ 的SV波、SH波绝对速度结构剖面, 并分析了径 向各向异性结构特征. 三大构造区地壳结构强烈的横 向和垂向不均匀性特征, 以及与克拉通中-西部北段地 壳结构的差异对比, 可能反映各块体经历了不同的复 杂演化历史和后期改造过程. 本文的主要结论如下:

(1) 克拉通中部南段地壳速度结构变化复杂, 广泛 存在壳内低速体, 地壳已经被改造. 陕西-山西裂陷区 及附近区域的下地壳至壳幔边界表现出强的正径向 各向异性特征, 可能与中-新生代地幔基性-超基性铁 镁质物质底侵有关. 中部带南段的壳内低速体, 可能 是地壳被中-新生代构造和岩浆活动改造的反映.

(2) 克拉通西部鄂尔多斯南段整体仍保留着稳定 的克拉通属性, 地壳未遭受明显改造. 大尺度且较厚的 浅部低速单斜结构, 可能与显生宙时期鄂尔多斯盆地 的整体掀斜, 以及晚白严世以来鄂尔多斯东隆西降、 遭受强烈的差异剥蚀有关. 该地区地壳速度结构相对 简单均一, 中-下地壳表现为大尺度的正径向各向异 性, 可能反映该区域还保存了克拉通形成演化早期的 结构特征.

(3) 克拉通中-西部南、北段地壳结构相似性和差 异性并存. 西部南、北段总体上都表现出稳定古老克
拉通地壳特征, 具有大尺度的成层性结构. 我们发现, 虽然鄂尔多斯北段广泛分布显著的壳内低速体, 但其 南段并不明显, 壳内低速体结构并不贯穿整个块体内 部. 中部南、北段地壳都表现出局部被改造特征, 但 径向各向异性结构和壳内低速体分布存在差异. 克拉 通中-西部的南、北地壳结构差异, 可能与古元古时期 华北克拉通拼合之前及之后, 受不同的构造事件的差 异影响有关. 要全面认识克拉通中-西部的地壳结构 特征及其演化过程, 还需要进一步开展三维结构研究.

(4) 祁连造山带东南部中地壳存在近平行且自西 向东逐渐变弱、厚 $10 \mathrm{~km}$ 的低速层. 祁连造山带与鄂 尔多斯交界的六盘山断裂带附近 20km深度以上地壳 速度较低, 地壳结构变化复杂, 与该边界带处显著的 地壳构造变形相对应. 祁连地区伴随着较强烈的现今 地震活动性, 其壳内低速层的形成很可能与青藏高原 的东北向生长相关. 由于受到坚硬的鄂尔多斯块体的 阻挡, 该区域壳内叠置增厚, 发生强烈的剪切韧性变 形, 力学强度变弱, 从而表现出低速特征, 但不支持与 青藏高原中下地壳流有关.

致谢中国科学院地质与地球物理研究所地震台阵实 验室提供流动地震数据资料; 中国科学技术大学姚华建 教授提供频散分析GUI软件; 美国圣路易斯大学Robert B. Herrmann教授公开的地震学计算程序CPS软件包; 中国 科学院地质与地球物理研究所郑天愉研究员的指导和讨 论; 两位评审专家严谨和建设性的建议, 在此一并致谢.

\section{参考文献}

常利军, 王椿镛, 丁志峰, 周民都, 杨建思, 徐智强, 姜旭东, 郑秀芬. 2008. 青藏高原东北缘上地幔各向异性研究. 地球物理学报, 51: 431-438

陈九辉, 刘启元, 李顺成, 郭飙, 赖院根. 2005. 青藏高原东北缘-鄂尔 多斯地块地壳上地幔 $\mathrm{S}$ 波速度结构. 地球物理学报, 48: 333-342 程先琼, 朱介寿, 蔡学林. 2011. 中国大陆Rayleigh面波衰减特征研 究. 中国地质, 38: 251-262

刘池洋, 赵红格, 桂小军, 岳乐平, 赵俊峰, 王建强. 2006. 鄂尔多 斯盆地演化-改造的时空坐标及其成藏(矿)响应. 地质学报, 80: 617-638

邓军, 王庆飞, 黄定华, 高帮飞, 杨立强, 徐浩. 2005. 鄂尔多斯盆地 基底演化及其对盖层控制作用. 地学前缘, 12: 91-99

范俊喜, 马瑾, 甘卫军. 2003. 鄂尔多斯地块运动的整体性与不同方向 边界活动的交替性. 中国科学 $\mathrm{D}$ 辑: 地球科学, 33(增刊): 119-128 
高锐, 王海燕, 王成善, 尹安, 张玉修, 李秋生, 郭形楼, 李文辉. 2011. 青藏高原东北缘岩石圈缩短变形. 地球学报, 32: 513-520

嘉世旭, 张先康. 2005. 华北不同构造块体地壳结构及其对比研究. 地球物理学报, 48: 611-620

李三忠, 赵国春, 孙敏. 2016. 华北克拉通早元古代拼合与Columbia 超大陆形成研究进展. 科学通报, 61: 919-925

李松林, 张先康, 张成科, 赵金仁, 成双喜. 2002. 玛沁-兰州-靖边地震 测深剖面地壳速度结构的初步研究. 地球物理学报, 45: 210-217 李志伟, 郝天珧, 徐亚. 2011. 华北克拉通上地幔顶部构造特征: 来 自台站间Pn波到时差成像的约束. 科学通报, 56: 962-970

邱瑞照, 李廷栋, 邓晋福, 周肃, 李金发, 肖庆辉, 吴宗絮, 赵国春. 2004. 华北地区三类岩石圈的壳幔岩石学结构与化学结构及其 大陆动力学意义. 岩石矿物学杂志, 23: 127-140

汤吉, 詹艳, 赵国泽, 邓前辉, 王继军, 陈小斌, 赵俊猛, 宣飞. 2005. 青藏高原东北缘玛沁-兰州-靖边剖面地壳上地幔电性结构研究. 地球物理学报, 48: 1205-1216

王伟涛, 倪四道, 王宝善. 2012. 中国中东部地震台站噪声互相关函 数中面波前驱信号的分析研究. 地球物理学报, 55: 503-512

危自根, 储日升, 陈凌. 2015. 华北克拉通地壳结构区域差异的接收 函数研究. 中国科学: 地球科学, 45: 1504-1514

吴福元, 徐义刚, 高山, 郑建平. 2008. 华北岩石圈减薄与克拉通破 坏研究的主要学术争论. 岩石学报, 24: 1145-1174

吴福元, 徐义刚, 朱日祥, 张国伟. 2014. 克拉通岩石圈减薄与破坏. 中国科学: 地球科学, 44: 2358-2372

徐义刚, 李洪颜, 庞崇进, 何斌. 2009. 论华北克拉通破坏的时限. 科 学通报, 54: 1974-1989

许志琴, 徐惠芬, 张建新, 李海兵, 朱志直, 曲景川, 陈代璋, 陈金禄, 杨开春. 1994. 北祁连走廊南山加里东俯冲杂岩增生地体及其 动力学. 地质学报, 68: 1-15

杨文采. 1997. 地球物理反演的理论与方法. 北京: 地质出版社

张培震, 沈正康, 王敏, 甘卫军. 2004. 青藏高原及周边现今构造变 形的运动学. 地震地质, 26: 367-377

赵国泽, 詹艳, 王立凤, 王继军, 汤吉, 陈小斌, 肖骑涁. 2010. 鄂尔多 斯断块地壳电性结构. 地震地质, 32: 345-359

朱日祥, 陈凌, 吴福元, 刘俊来. 2011. 华北克拉通破坏的时间、范围 与机制. 中国科学: 地球科学, 41: 583-592

朱日祥, 范宏瑞, 李建威, 孟庆任, 李胜荣, 曾庆栋. 2015. 克拉通破 坏型金矿床. 中国科学: 地球科学, 45: 1153-1168

朱日祥, 徐义刚, 朱光, 张宏福, 夏群科, 郑天愉. 2012. 华北克拉通 破坏. 中国科学: 地球科学, 42: 1135-1159

朱日祥, 郑天愉. 2009. 华北克拉通破坏机制与古元古代板块构造 体系. 科学通报, 54: 1950-1961

Bao X W, Song X D, Xu M J, Wang L S, Sun X X, Mi N, Yu D Y, Li H. 2013. Crust and upper mantle structure of the North China Craton and the NE Tibetan Plateau and its tectonic implications. Earth Planet Sci Lett, 369-370: 129-137
Bensen G D, Ritzwoller M H, Barmin M P, Levshin A L, Lin F, Moschetti M P, Shapiro N M, Yang Y. 2007. Processing seismic ambient noise data to obtain reliable broad-band surface wave dispersion measurements. Geophys J Int, 169: 1239-1260

Bensen G D, Ritzwoller M H, Yang Y J. 2009. A 3-D shear velocity model of the crust and uppermost mantle beneath the United States from ambient seismic noise. Geophys J Int, 177: 1177-1196

Birch F. 1961. The velocity of compressional waves in rocks to 10 kilobars: 2. J Geophys Res, 66: 2199-2224

Carlson R W, Pearson D G, James D E. 2005. Physical, chemical, and chronological characteristics of continental mantle. Rev Geophys, 43: RG1001

Campillo M, Roux P. 2014. Seismic imaging and monitoring with ambient noise correlations. Treatise Geophys, 1: 256-271

Chen L, Cheng C, Wei Z G. 2009. Seismic evidence for significant lateral variations in lithospheric thickness beneath the central and western North China Craton. Earth Planet Sci Lett, 286: 171-183

Chen L, Jiang M M, Yang J H, Wei Z G, Liu C Z, Ling Y. 2014. Presence of an intralithospheric discontinuity in the central and western North China Craton: Implications for destruction of the craton. Geology, 42: $223-226$

Chen L, Tao W, Zhao L, Zheng T Y. 2008. Distinct lateral variation of lithospheric thickness in the Northeastern North China Craton. Earth Planet Sci Lett, 267: 56-68

Chen L, Zheng T Y, Xu W W. 2006. A thinned lithospheric image of the Tanlu Fault Zone, eastern China: Constructed from wave equation based receiver function migration. J Geophys Res, 111: B09312

Chen Y L, Niu F L. 2016. Joint inversion of receiver functions and surface waves with enhanced preconditioning on densely distributed CNDSN stations: Crustal and upper mantle structure beneath China. J Geophys Res-Solid Earth, 121: 743-766

Cheng C, Chen L, Yao H J, Jiang M M, Wang B Y. 2013. Distinct variations of crustal shear wave velocity structure and radial anisotropy beneath the North China Craton and tectonic implications. Gondwana Res, 23: 25-38

Davis G A, Zhang Y D, Wang C, Darby B J, Zhang C H, Gehrels G. 2001. Mesozoic tectonic evolution of the Yanshan fold and thrust belt, with emphasis on Hebei and Liaoning Provinces northern China. GSA Memoir, 194: 171-197

Dong H, Wei W B, Ye G F, Jin S, Jones A G, Jing J, Zhang L T, Xie C L, Zhang F, Wang H. 2014. Three-dimensional electrical structure of the crust and upper mantle in Ordos Block and adjacent area: Evidence of regional lithospheric modification. Geochem Geophys Geosyst, 15: 2414-2425

Fu Y V, Gao Y, Li A B, Shi Y T. 2015. Lithospheric shear wave velocity and radial anisotropy beneath the northern part of North China from 
surface wave dispersion analysis. Geochem Geophys Geosyst, 16: 2619-2636

Griffin W L, Zhang A, O'Reilly S Y, Ryan C G. 1998. Phanerozoic evolution of the lithosphere beneath the Sino-Korean craton. In: Flower M F J, Chung S L, Lo C H, Lee T Y, eds. Mantle Dynamics and Plate Interactions in East Asia. Am Geophys Union Geodyn Ser, 27: $107-126$

Guo X Y, Gao R, Li S Z, Xu X, Huang X F, Wang H Y, Li W H, Zhao S J, Li X Y. 2016. Lithospheric architecture and deformation of NE Tibet: New insights on the interplay of regional tectonic processes. Earth Planet Sci Lett, 449: 89-95

Guo Z, Chen Y J. 2016. Crustal structure of the eastern Qinling orogenic belt and implication for reactivation since the Cretaceous. Tectonophysics, 683: 1-11

Harmon N, Rychert C, Gerstoft P. 2010. Distribution of noise sources for seismic interferometry. Geophys J Int, 183: 1470-1484

Herrmann R B. 2013. Computer programs in seismology: An evolving tool for instruction and research. Seismol Res Lett, 84: 1081-1088

Herrmann R B, Ammon C J. 2002. Computer Programs in Seismology: Surface Waves, Receiver Functions and Crustal Structure. vol. 3.30. Saint Louis Univ, St Louis, Mo

Hu S B, He L J, Wang J Y. 2000. Heat flow in the continental area of China: A new data set. Earth Planet Sci Lett, 179: 407-419

Huang Z X, Li H Y, Zheng Y J, Peng Y J. 2009. The lithosphere of North China Craton from surface wave tomography. Earth Planet Sci Lett, 288: $164-173$

Jiang C X, Yang Y J, Zheng Y. 2014. Penetration of mid-crustal low velocity zone across the Kunlun Fault in the NE Tibetan Plateau revealed by ambient noise tomography. Earth Planet Sci Lett, 406: 81-92

Jiang M M, Ai Y S, Chen L, Yang Y J. 2013. Local modification of the lithosphere beneath the central and western North China Craton: 3-D constraints from Rayleigh wave tomography. Gondwana Res, 24: 849-864

Li H Y, Shen Y, Huang Z X, Li X F, Gong M, Shi D H, Sandvol E, Li A B. 2014. The distribution of the mid-to-lower crustal low-velocity zone beneath the northeastern Tibetan Plateau revealed from ambient noise tomography. J Geophys Res-Solid Earth, 119: 1954-1970

Li S G, Xiao Y L, Liou D L, Chen Y Z, Ge N J, Zhang Z Q, Sun S S, Cong B L, Zhang R Y, Hart S R, Wang S S. 1993. Collision of the North China and Yangtse Blocks and formation of coesite-bearing eclogites: Timing and processes. Chem Geol, 109: 89-111

Li Y H, Wu Q J, Zhang F X, Feng Q Q, Zhang R Q. 2011. Seismic anisotropy of the Northeastern Tibetan Plateau from shear wave splitting analysis. Earth Planet Sci Lett, 304: 147-157

Liu D Y, Nutman A P, Compston W, Wu J S, Shen Q H. 1992. Remnants of $\geq 3800$ Ma crust in the Chinese part of the Sino-Korean Craton.
Geology, 20: 339-342

Liu Q Y, van der Hilst R D, Li Y, Yao H J, Chen J H, Guo B, Qi S H, Wang J, Huang H, Li S C. 2014. Eastward expansion of the Tibetan Plateau by crustal flow and strain partitioning across faults. Nat Geosci, 7: 361-365

Luo Y H, Yang Y J, Xu Y G, Xu H R, Zhao K F, Wang K. 2015. On the limitations of interstation distances in ambient noise tomography. Geophys J Int, 201: 652-661

Sabra K G, Gerstoft P, Roux P, Kuperman W A, Fehler M C. 2005. Extracting time-domain Green's function estimates from ambient seismic noise. Geophys Res Lett, 32: L03310

Schwab F A, Knopoff L. 1972. Fast surface wave and free mode computations. Method Comput Phys Adv Res Appl, 11: 87-180

Shapiro N M, Campillo M. 2004. Emergence of broadband Rayleigh waves from correlations of the ambient seismic noise. Geophys Res Lett, 31: L07614-5

Wang C Y, Sandvol E, Zhu L P, Lou H, Yao Z X, Luo X H. 2014. Lateral variation of crustal structure in the Ordos block and surrounding regions, North China, and its tectonic implications. Earth Planet Sci Lett, 387: 198-211

Wei Z G, Chen L, Jiang M M, Ling Y. 2015. Lithospheric structure beneath the central and western North China Craton and the adjacent Qilian orogenic belt from Rayleigh wave dispersion analysis. Tectonophysics, 646: 130-140

Wei Z G, Chen L, Li Z W, Ling Y, Li J. 2016. Regional variation in Moho depth and Poisson's ratio beneath eastern China and its tectonic implications. J Asian Earth Sci, 115: 308-320

Wei Z G, Chen L, Wang B Y. 2013. Regional variations in crustal thickness and $V_{\mathrm{p}} / V_{\mathrm{s}}$ ratio beneath the central-western North China Craton and adjacent regions. Geol J, 48: 531-542

Wei Z G, Chen L, Xu W W. 2011. Crustal thickness and $V_{\mathrm{p}} / V_{\mathrm{s}}$ ratio of the central and western North China Craton and its tectonic implications. Geophys J Int, 186: 385-389

Wu F Y, Yang J H, Wilde S A, Zhang X O. 2005. Geochronology, petrogenesis and tectonic implications of Jurassic granites in the Liaodong Peninsula, NE China. Chem Geol, 221: 127-156

Xiao W J, Windley B F, Hao J, Zhai M G. 2003. Accretion leading to collision and the Permian Solonker suture, Inner Mongolia, China: Termination of the central Asian orogenic belt. Tectonics, 22: 1069

Xiao W J, Windley B F, Yong Y, Yan Z, Yuan C, Liu C Z, Li J L. 2009. Early Paleozoic to Devonian multiple-accretionary model for the Qilian Shan, NW China. J Asian Earth Sci, 35: 323-333

Xie J Y, Ritzwoller M H, Shen W S, Yang Y J, Zheng Y, Zhou L Q. 2013. Crustal radial anisotropy across Eastern Tibet and the Western Yangtze Craton. J Geophys Res-Solid Earth, 118: 4226-4252

Xu Y G. 2001. Thermo-tectonic destruction of the archaean lithospheric 
keel beneath the sino-korean craton in china: Evidence, timing and mechanism. Phys Chem Earth Part A-Solid Earth Geodesy, 26: $747-757$

Xu Y G. 2007. Diachronous lithospheric thinning of the North China Craton and formation of the Daxin'anling-Taihangshan gravity lineament. Lithos, 96: 281-298

Yang Y J, Ritzwoller M H, Levshin A L, Shapiro N M. 2007. Ambient noise Rayleigh wave tomography across Europe. Geophys J Int, 168: 259-274

Yao H J, Beghein C, van der Hilst R D. 2008. Surface wave array tomography in SE Tibet from ambient seismic noise and two-station analysis-II. Crustal and upper-mantle structure. Geophys J Int, 173: 205-219

Yao H J, Campman X, de Hoop M V, van der Hilst R D. 2009. Estimation of surface wave Green's functions from correlation of direct waves, coda waves, and ambient noise in SE Tibet. Phys Earth Planet Inter, 177: $1-11$

Yao H J, van der Hilst R D, de Hoop M V. 2006. Surface-wave array tomography in SE Tibet from ambient seismic noise and two-station analysis - I. Phase velocity maps. Geophys J Int, 166: 732-744

Yao H J, van der Hilst R D. 2009. Analysis of ambient noise energy distribution and phase velocity bias in ambient noise tomography, with application to SE Tibet. Geophys J Int, 179: 1113-1132

Yu C Q, Chen W P, Ning J Y, Tao K, Tseng T L, Fang X D, Chen Y J, van der Hilst R D. 2012. Thick crust beneath the Ordos plateau: Implications for instability of the North China craton. Earth Planet Sci Lett, 357-358: 366-375

Zeng X F, Ni S D. 2010. A persistent localized microseismic source near the Kyushu Island, Japan. Geophys Res Lett, 37: L24307

Zeng X F, Ni S D. 2011. Correction to "A persistent localized microseismic source near the Kyushu Island, Japan”. Geophys Res Lett, 38:
L16320

Zhao G C, Wilde S A, Cawood P A, Sun M. 2001. Archean blocks and their boundaries in the North China Craton: Lithological, geochemical, structural and $P-T$ path constraints and tectonic evolution. Precambrian Res, 107: 45-73

Zhao G C, Sun M, Wilde S A, Sanzhong L. 2005. Late Archean to Paleoproterozoic evolution of the North China Craton: Key issues revisited. Precambrian Res, 136: 177-202

Zhao L, Allen R M, Zheng T Y, Hung S H. 2009. Reactivation of an Archean craton: Constraints from P- and S-wave tomography in North China. Geophys Res Lett, 36: L17306

Zhai M, Liu W J. 2003. Palaeoproterozoic tectonic history of the North China craton: A review. Precambrian Res, 122: 183-199

Zhang Y Q, Mercier J L, Vergély P. 1998. Extension in the graben systems around the Ordos (China), and its contribution to the extrusion tectonics of south China with respect to Gobi-Mongolia. Tectonophysics, 285: 41-75

Zheng J P, O'Reilly S Y, Griffin W L, Lu F X, Zhang M, Pearson N J. 2001. Relict refractory mantle beneath the eastern North China Block: Significance for lithosphere evolution. Lithos, 57: 43-66

Zheng T Y, Zhao L, Zhu R X. 2008. Insight into the geodynamics of cratonic reactivation from seismic analysis of the crust-mantle boundary. Geophys Res Lett, 35: L08303

Zheng T Y, Zhao L, Zhu R X. 2009. New evidence from seismic imaging for subduction during assembly of the North China Craton. Geology, 37: $395-398$

Zheng Y, Shen W S, Zhou L Q, Yang Y J, Xie Z J, Ritzwoller M H. 2011. Crust and uppermost mantle beneath the North China Craton, northeastern China, and the Sea of Japan from ambient noise tomography. J Geophys Res, 116: B12312 